Aus der dermatologischen Klinik der kgl. Universität zu Parma.

(Vorstand: Prof. M. Pelagatti.)

\title{
Über das sog. Sarcoma idiop. multiplex haemorrhagicum (Kaposi).
}

Klinische und histologische Beiträge.

Von

\author{
Dr. G. B. Dalla Favera, \\ Assistenten der Klinik.
}

(Hiezu Taf. IX-XI.)

Die folgenden Ausführungen betreffen einige typische Fälle des in dieser Gegend nicht gerade sehr selten vorkommenden Sarcoma idiop. mult. haemorrhagicum. Die mitgeteilten Fälle scheinen uns in bezug auf klinische Erscheinungen, Verlauf und anatomische Veränderungen von einigem Interesse zu sein; so konnte u. a. in zwei zur Sektion gelangten Fällen die histologische Untersuchung der Sarkomherde der inneren Organe (Lungen, Gastrointestinaltraktus, Leber, Lymphdrüsen) systematisch durchgeführt werden. Den eigenen Beobachtungen anknüpfend, wurde die Sichtung der einschlägigen Literatur vorgenommen, mit spezieller Rücksicht auf einige bisher nicbt genug gewürdigte Punkte.

Es kann wohl kein Zweifel bestehen, daß es sich bei dem sog. S. i. m. h. um ein gut definiertes Krankheitsbild handelt. $O b$ und inwiefern das Leiden mit anderen Krankheiten, insbesondere mit dem, von Kaposi aufgestellten, zweiten Typus der allgemeinen Hautsarkomatose ${ }^{1}$ ) verwandt ist, wird heut-

1) In neuerer Zeit hat Polland (Archiv, Bd. CIV, p. 69) vorgeschlagen, diese Art der allgemeinen Hautsarkomatose nach dem 
zutage noch umstritten. Fan $\mathbf{0}$, der 1907 in einer ausführlichen Arbeit über die Sarkome und sarkoiden Geschwülste der Haut (Archiv, Bd. LXXXIII) auch diese Frage berücksichtigt hat, behauptete, daß die Typen $a$ ) und $b$ ) der allgemeinen Hautsarkomatose als Formen einer und derselben Krankheit aufzufassen sind. Wir verzichten darauf, an dieser Stelle auf diesen strittigen Punkt näher einzugehen, möchten aber auf Grund eines jüngst untersuchten Falles von Spieglerscher Sarkomatose bemerken, daß es sehr zweifelhaft scheinen will, ob die Ansicht Fan os zu billigen sei.

Wir lassen nun die Beschreibung unserer Fälle von S. i. m. h. folgen.

Fall I. F. R., 52 J. alt, verheiratet, Eisenbahnbeamter aus Parma.

Anamnese. Eine Schwester des Patienten starb an Lungen- und Knochentuberkulose. Patient ist seit etwa 30 Jahren verheiratet und hat 3 gesunde Kinder. Patient gibt an, immer ein ruhiges Leben geführt zu haben; keine übermäßige Anstrengung. Potus wird zugestanden. Pat. hat nie ernstliche Krankheiten durchgemacht. Vor etwa 15 Jahren litt er an Erysipel des r. Beines. Die jetzige Hautkrankheit begann vor 5 Jahren mit der Anschwellung beider Unterschenkel; die Hände wurden 2 Jahre später befallen. Auf Rat von Prof. Mibelli, dessen Sprechstunde Pat. Juli 1908 aufsuchte, hat er sich vom Hausarzt mit Einspritanngen von Natr. arsen. längere Zeit behandeln lassen. Der Krfolg soll befriedigend gewesen sein. Pat. ist seither auch eine Zeit lang mit Röntgenstrahlen behandelt worden.

Status vom 28./XI. 1909: Mittelgroßes Individuum von regelmäßigem Knochenbau, in gutem Ernährungszustand. Die Untersuchung der inneren Organe ergibt nichts Abnormes.

Hautveränderungen. Am r. Unterarme, namentlich auf der Extensionfläche findet sich eine Anzahl von verschieden großen, sehr wenig prominierenden, fleckigen Effloreszenzen von stahlgrauer Farbe. Bei der Betastung erkennt man, daß diesen Farbenveränderungen der Haut ausgedehnte, sebr hart sich anfühlende Infiltrate der Kutis und der Subkutis entsprechen. Die Haut der r. Hand ist, mit Ausnabme der Eminentia tenar, verdickt, verhärtet und bleigrau verfärbt. Auf dem Kubitalrand ist eine talergroße Erosion mit Krustenbildung vorhanden. Handteller polsterartig aufgetrieben. Die Haut der Finger ist, ebenso wie. die der Hand, verdickt, verhärtet, auf der Unterlage nicht verschieblich. Die Beschaffenheit der Fingerhaut, namentlich des Ringfingers, erinnert in mancher Hinsicht an Sklerodermie. Diesbezüglich sei bemerkt, daß der Fall von einem spezialisten als Sklerodermie diagno-

Namen des verdienten Forschers, der die ersten diesbezüglichen Fälle beschrieben hat, als Sarcomatosis cutis Spiegler zu benennen. 
stiziert wurde. Der l. Unterarm und die l. Hand sind in geringerem Maße befallen. Die Haut der Hand ist etwas verdickt und verhärtet, aber behält ihre normale Farbe bei; auf dem Innenrand des 1 . Zeigefingers finden sich mehrere kutane Knötchen, die ebenfalls keine Veränderung der normalen Hautfarbe aufweisen. Am r. Oberschenkel auf der Aulenseite finden sich zwei infiltrierte, wenig erhabene, livide Flecken; drei ähnliche Flecken finden sich auf der Vorderseite des l. Oberschenkels. In der l. Inguinalgegend findet sich eine fünfmarkstückgroße, dunkelrote, derbe Infiltrationsplatte mit prominierenden Knötchen. Die Haut beider Unterschenkel erscheint gleichmäßig verdickt, von brettharter Konsistenz und haftet an der Unterlage. Füße frei von Veränderungen. Das Präputium ist in seinen hinteren Partien diffus infiltriert; hie und da fühlt man umschriebene knotige Verdickungen. Das Frenulum ist verdickt, verhärtet, dunkelviolett verfärbt. Auch die Harnröhrenmündung zeigt sich wulstig geschwollen und bläulich verfärbt. Bei Besichtigung der Mundschleimhaut findet man auf dem harten Gaumen, rechts von der Medianlinie, einen zweipfennigstückgroßen, bläulichen Fleck; ein kleinerer, ähnlicher Herd findet sich linkerseits. Urinbefund normal. Wassermann negativ. Blutuntersuchung: r. Blutkörperchen 4,200.000, w. 26.320, Hämoglobin (Fle i s c hl) 85 .

Am 15./VII. 1910 stellte sich Pat. wieder vor. In der Zwischenzeit hat er aus äußeren Gründen keine Kur machen können. Bei der klinischen Untersuchung konnten wir folgendes feststellen: Allgemeinzustand gut. Aus der Infiltrationsplatte der 1. Leistengegend sind einige bohnengroße, gestielte Knoten mit erodierter Oberfläche herausgewachsen. Die r. Hand lietet fast dasselbe klinische Bild wie vorher. An der l. Hand dagegen hat die Krankheit bedeutende Fortschritte gemacht, indem eine Unmenge von kleinen bläulichen Knötchen auf dem Handrücken und auf die Finger aufgeschossen sind. Was aber hier besouders die Aufmerksamkeit fesselt, ist das Vorhandensein von Ly mphysten. Sie finden sieh in der Zahl von etwa 4-5 auf dem Handrücken zwischen den derben Knötchen eingestreut; ferner finden sich 3 kirschkerngroße Zysten auf dem Rücken des Zeigefingers und 2 kleinere auf dem Ringfinger. Endlich sieht man eine hanfkorngroße Zyste auf dem Rücken des kleinen Fingers und diese ist dadurch bemerkenswert, daß sie in völlig gesunder Haut sitzt und einer kleinen Brandblase nicht unähnlich aussieht. Beim Einstechen mit einer Nadel entleert sich aus den Lymphzysten eine rosa gefärbte Flüssigkeit. Pat. klagt über stechende Schmerzen in den Händen.

Vom 15./VII.-30./X. 1910 blieb der Kranke in unserer Behandlung. Diese bestand zunächst in 45 Injekt. von Natr. arsen. (insgesamt $60 \mathrm{cg}$ ). Keine sichtbare Besserung. Dann wurden die Einspritzungen unterbrochen und die neulich von Winkler empfohlene Einführung von Arsen durch Elektrophor ose begonnen. Die l. Hand wurde mit einer dicken Lage von Watte, die mit einer Lösung von Ac. arsenicosum 1 : 5000 durchtränkt war, umwickelt; darüber ein Stanniolbelag, der mit dem negativen Pol einer Batterie in Verbindung gesetzt wurde. Stromstärke 4 Miliampère, Sitzungsdauer 20-35 Minuten. Es wurden insgesamt 29 derartige Sitzungen aus- 
gefübrt. Sofort nach der Sitzung war eine deutliche Abblassung der Herde zu sehen, die mehr oder weniger lange anhielt; die Schmerzen an der behandelten Hand ließen etwas nach. Wir konnten aber auch durch dieses Verfahren keine Rückbildung der Krankheitsherde erzielen, was durch exakte Messungen der affizierten Partien vor und nach der Behandlung klargelegt wurde. Betreff der Behandlung sei noch erwähnt, daß wir Fibrolysin in einige, besonders harte Herde des 1. Oberschenkels versuchsweise injizierten, jedoch ohne jegliche Beeinflussung der Krankheitsprodukte. Auch von der Anwendung des von Schwimmer zur Beseitigung der Suhmerzen empfohlenen $\mathrm{Phenazetin}$ sahen wir keinen Erfolg.

Nachdem Pat. längere Zeit ausgeblieben war, stellte er sich am 10./XII. 1910 wieder vor. Da konnten wir wahrnehmen, daß die Herde, die während der vorherigen Behandlung wenn auch nicht zurückgegangen, so doch stationär geblieben waren, nach Aussetzen der Arsendarreichung ein ganz merkliches Wachstum erfahren hatten. Zur Zeit wird Pat. mit Arseneinspritzungen und X-Strahlen behandelt.

Fall II. C. G., 55 Jahre alt, ledig, Schuster aus Polesine (Parma).

Anamnese. Keine hereditäre Belastung. Vor 13 Jahren wurde Pat. wegen eines Leistenhodens operiert. Die jetzige Hautkrankheit begann vor 2 Jahren mit verrukösen Wacherungen am Außenrand des r. Fußes. Die diffuse Schwellung des $r$. Beines soll erst seit 2 Monaten bestehen.

Status vom 28./VII. 1909: Mittelgroßes Individuum von regelmäßigem Knochenbau, in leidlich gutem Ernährungszustand. Die Untersuchung der inneren Organe ergibt normale Verhältnisse. Leichte periphere Arteriosklerose.

Was das Bild der Dermat ose anbetrifft, so ist die r. untere Extremität in ihrer ganzen Länge ödematös angeschwollen: besonders der Fußrücken und das untere Drittel des Unterschenkels erscheinen an Umfang bedeutend vergrößert. Das Ödem ist ziemlich weich. An dem Außenrand des Fußes bis zum Malleolus ext. findet sich ein ausgedehnter, dunkelroter, gegen die Umgebung wenig scharf abgesetzter, infiltrierter Fleck: auf demselben sieht man in dichter Anordnung prominente beerenförmige Knötchen. Vereinzelte Knötchen sind auch in der Umgebung verstreut, manche derselben weisen die Zeichen einer frischen Blutung auf. Weiter oben, auf der Außenseite des Kniegelenkes, sieht man 4 nebeneinanderliegende, dem Verlauf einer subkutanen Vene entlang linienartig angeurdnete Knötchen. In der Leistengegend findet sich eine $12 \mathrm{~cm}$ lange, tief eingezogene Operationsnarbe; etwas darunter sieht man einen ausgedehnten ( $\mathrm{cm} 2 \times \mathrm{cm} 7$ ), der Leistenfalte parallel gerichteten, braunroten Infiltrationsherd mit höckerichter Oberfläche. Auf der Glans penis finden sich 5 biaurote Knötchen. Vereinzelte Knötchen finden sich auch auf der r. Hälfte der Oberlippe, auf dem freien Rande des 1. oberen Augenlides, auf der hinteren Fläche des r. Unterarmes und auf der Außen- 
seite des r. Handgelenkes. Die Haut des übrigen Körpers und die sichtbaren Schleimhäute zeigen keinerlei Veränderungen.

Urinbefund normal. Was s ermann negativ. Blutbefund: r. Blutkörperchen 3,916.000, w. 9800 (Lymphozyten $8.5 \%$, große mononukleäre $28 \cdot 2 \%$, Übergangsformen $9.9 \%$, polymorphkernige neutrophyle Leukoz. $50.8 \%$, eosinophile $1.6 \%$, basophile $1 \%$ ), Hämoglobin (Fleischl) 65 . Zwecks mikroskopischer Untersuchung wurde ein kleines Stück der Infiltrationsplatte der Leistengegend exzidiert; bei dieser Gelegenheit impfte ich ein Stückchen vom Geschwulstgewebe in einer Hauttasche in den l. Oberschenkel ein. Die Inokulation fiel völlig negativ aus.

Während des kurzen Aufenthaltes in der Klinik wurde der Pat. mit Injekt. von Natr. arsen. (im ganzen $2.5 \mathrm{cg}$ ) behandelt; am r. Bein lokal mit heißen Umschlägen. Pat. wird mit dem Rate entlassen (14. August 1909), eine Arsenkur durchzumachen.

19./XII. 1909. Der Kranke stellt sich in der Poliklinik wieder vor. In der Zwischenzeit hat aus äußeren Gründen keine Behandlung stattgefunden. Bei der Untersuchung siebt man, daß die Schwellung des r. Beines bedeutend abgenommen hat. Die Krankheitsherde der Malleolargegend sind kleiner geworden, ihre Farbe viel heller. Das auf der Außenseite des $r$. Handgelenkes sich befindende Knötchen ist kaum sichtbar. Die Infiltrate der Glans penis sind stationär.

16./IV. 1910. Seit Weihnachten hat Pat. Solutio ars. Fowleri genommen. Der Allgemeinzustand ist gut. Die Krankheitsherde des r. Beines sind noch kleiner geworden. Die übrigen Herde sind unverändert. Auf dem weichen Gaumen linkerseits ist ein linsengroßer, blauroter Fleck aufgetreten.

Fall III. D. E., 52 Jahre alt, verheiratet, Taglöhner aus Parma.

Keine bereditäre Belastung. Vor 11 Jahren akquirierte Pat. Lues. Er ist seit 6 Jahren verheiratet und hat 2 gesunde Kinder. Pat. ist starker Raucher und Potator. Das jetzige Hautleiden soll im Jahre 1902 begonnen haben. Pat. bemerkte zunächst einige blaurote Flecken an der Innenfläche des 1. Oberschenkels. Kurze Zeit darnach trat eine diffuse Anschwellung des I. Fußes und Unterschenkels auf. Pat. ist während der langjährigen Krankheit nie behandelt worden.

Status bei der Aufnahme des Patienten (2./IV. 1909): Mittelgroßes Individuum von regelmäßigem Knochenbau, in heruntergekommenem Ernährungszustand. Sichtbare Schleimhäute bla 3 , Hautfarbe gelblich. Die Dermatose ist sehr verbreitet. Am Kopf, auf der Stirne, etwas links von der Glabella sieht man einen länglich-ovalen, zweimarkstückgroßen, erbabenen, blaurot gefärbten, infiltrierten Fleck; das sehr harte Infiltrat ist auf den untenliegenden Schichten verschiebbar. An der r. Ecke des Unterkiefers findet sich ein ähnlicher, talergroßer, ca. $1 \mathrm{~cm}$ prominierender Knoten von dunkelroter Farbe und leicht höckeriger Oberfläche. Am Ha ls e, an der vorderen Hälfte, finden sich 4 umschriebene, erbsen- bis maiskorngroße Knötchen. Auf dur vorderen $\mathrm{T}$ hor axwand, entsprechend dem 3. linken Interk ostalraum, sieht man einen größeren, 
knotigen Herd von einem grüngelblichen Hof umgeben : um den größeren Herd gruppieren sich 4 kleinere Knötchen. Eine ähnliche Effloreszenz findet sich auf dem Rü cken, in der Medianlinie, entsprechend dem Dornfortsatz des 2. Rückenwirbels; in der nächsten Umgebung finden sich 4 linsengroße, kaum erhabene, infiltrierte Flecken. Ferner findet sich ein ausgedehnter ( $\mathrm{cm} 4 \times \mathrm{cm} 2.5$ ) knotiger Herd entsprechend der Spina iliaca anterior superior. Die äußeren Genitalien sind stark befallen. Auf der Vorhaut, entsprechend der Raphe, findet sich ein haselnußgroßer, erhabener Tumor von dunkelbraunroter Farbe. Das Präputium läBt sich über die Glans nur unvollkommen zurückschlagen. Das innere Präputialblatt ist weißlichgrau verfärbt und weist eine Anzahl von eingesprengten bläulichen Knötchen auf. Die Eichel, soweit man sie freilegen kann, erscheint auf das Doppelte vergrößert, von dunkelblauroter Farbe und von brettharter Konsistenz. Der Urethralmündung entsprechend, findet sicb ein grubiges, tiefgreifendes Geschwür. Urinstrahl sehr dünn; am Schlusse der Miktion längeres Nachträufeln. Von dem Versuch, ein filiformes Bougie in die Harnröhre einzuführen, mußte ich wegen der eintretenden starken Blutung abstehen. Rechte un tere Extremität. An der Außenseite des r. Oberschenkels findet sich ein zweimarkstückgroßer, erhabener, dunkelroter Herd, daneben 5 linsenförmige bläuliche Knötchen. Die umgebende Haut zeigt sich in einer breiten Fläche (etwa $15 \mathrm{~cm}$. Durchmesser) grüngelblich verfärbt und fühlt sich verdickt und verhärtet an. An der Vorder- und Innenseite des r. Oberschenkels sehen wir in einer Ausdehnung von $20 \mathrm{~cm}$ Längs- zu $8 \mathrm{~cm}$ Querdurchmesser eine ähnliche diffuse Verfärbung der Haut mit zahlreichen, eingestreuten bläulichen Knötchen. Oben, in der Leistenfalte fühlt man unter der Haut eine derbe, auf der Unterlage nicht verschiebbare, geschwulstartige Masse, die offenbar den vergrößerten Inguinaldrüsen entspricht. An dem rechten Unterschenkel, abgesehen von einem kleinen infiltrierten Flecken auf deni Malleolus externus, nichts Abnormes. Die linke untere Extremität ist elephantiasisartig in toto angeschwollen; das Ödem läßt sich beim Fingerdruck nicht verdrängen. Inguinaldrüsen mächtig angeschwollen. In der linken Leistengegend eine handtellergroße Infiltrationsplatte mit prominierenden Knötchen. Auf der Innenfläche des 1. Oberschenkels findet sich ein sehr ausgedehntes $(\mathrm{cm} 11 \times \mathrm{cm} 7)$, längliches, plattenförmiges Infiltrat von dunkelroter Farbe; die Oberfäche zeigt eine Anzahl von hornigen, kegelförmig akuminierten Erhabenheiten, die ihr ein papillomatöses Aussehen verleihen. Nach der Entfernung der hornigen Auflagerungen durch einen Salizylvaselineverband kommen feinpapilläre, leicht blutende Wucherungen zutage. Die Haut des l. Unterschenkels und Fußes zeigt eine Anzahl von Flecken und Knötchen; manche Herde haben ein verruköses Aussehen angenommen. Bei Besichtigung der Mundschleimhaut sieht man 3 infiltrierte, erhabene Flecken auf dem harten und weichen Gaumen. Bei der Untersuchung der inneren Organe findet man links oberhalb und unterhalb der Klavikula leichte Verstärkung des Pektoralfremitus, Dämpfung des Lungenschalles, abge- 
schwächtes Vesikularatmen. I،eichte Verbreiterung der Ierzdämpfung nach links. Milz leicht vergrößert. Patient klagt beim Gehen über Schmerzen am linken Fuße.

Im Urin Spuren von Eiweiß. Blutbefund: r. Blutkörperchen 3,270.000, w. 37.200, Hämoglobin ( $\mathrm{Fle}$ is $\mathrm{chl}$ ) 65. Wassermann positiv.

Krankheitsverlauf. Wir behandelten den Kranken zunächst mit Arsazetininjektionen (im ganzen $6.60 \mathrm{~g}$ ) und später mit Einspritzungen von Natr. arsen. Nach den ersten Injektionen war eine leichte Besserung des Allgemeinbefindens nachzuweisen; aber die Besserung bielt nicht lange an. An den Krankheitsherden konnten wir nicht die geringste Spur von Rückbildung wahrnehmen. Da die Beschwerden beim Urinieren immer zunahmen und die Dilatation der Striktur wegen der starken Blutung nicht in Betracht gezogen werden konnte, wurde am 25./VI. 1909 die Amputation der Glans penis vorgenommen. Heilung per primam. In den folgenden Monaten Mai und Juni wurde der Allgemeinzustand des Pat. immer schlechter, trotz der fortgesetzten Arsendarreichung. Merkliche Abmagerung und Nachlassen der Kräfte. Atmung schwer, anhaltender Husten mit spärlichem Auswurf. Wëhrend der Nacht schwere asthmatische Anfälle. Bei der Untersuchung der Lungen war (außer der obenerwähnten Dämpfung an der l. Lungenspitze) nur ein diffuser Bronchialkatarrh nachzuweisen. Puls leidlich gut. Urin spärlich, Eiweiß $(0 \cdot 50 \%)$ enthaltend. Stuhlgang regelmäßig, nie blutig. Von der Arsenbehandlung wurde schlieBlich abgesehen; die Therapie bestand in der Verabreichung von Expektorantien und Herzmitteln. Während der Asthmaanfälle Morphium per os und subkutan. Bezüglich der $\mathrm{Hautaffektion}$ ist uns während der fast viermonatlichen Beobachtungszeit besonders die Häufigkeit der Blutungen um die Krankheitsherde aufgefallen. Wir konnten auch das Auftreten von Blutungen in anscheinend gesunden Hautgebieten (r. Oberund Unterschenkel) konstatieren. Die Hämorrhagie gab sich wie gewöhnlich durch die bekannte Verfärbung der Haut kund und ging häufig der Entwicklung eines kutanen Infiltrates voraus. Ein solcher Blutungsherd in der gesunden Haut auf der Außenseite des r. Oberschenkels wurde exzidiert und mikroskopisch untersucht. Am 22./VII. 1909 trat eine Verschlimmerung in dem Krankheitszustand ein. Harn sehr spärlich, Eiweiß $4 \%$. Bei der Untersuchung fiel eine leichte Rötung der Skrotalhaut auf; es wurde Erysipel vermutet. Zunehmende Herzschwäche. 24./VII. 1909 Exitus in coma.

Bei der Obduktion (16 Stunden nach dem Tode ausgeführt) fanden sich Sarkomknoten in der Trachea, in den Bronchien, in den Lungen, in dem Magen und Darm, ferner in den Krurallymphdrüsen und in den um die Aa. iliaca ext. und communis gelegenen Lymphdrüsen. L u ngen. Die Oberfläche beider Lungen zeigt eine Anzahl von flachen oder leicht erhabenen, bläulich gefärbten, ziemlich scharf begrenzten Herden. Manche Herde sind von einem dunkelroten, hämorrhagigchen Hof umgeben. Den Herden der Oberfläche entsprechen, beim Durchschnitt der Lungen, tiefgreifende, sich derb anfühlende Knoten des Parenchyms, 
in deren Bereich jede Spur von Alveolenparenchym verschwunden ist. Der größte Herd (über hühnereigroß) findet sich im Oberlappen der l. Lunge; die übrigen Knoten sind hanfkorn- bis walnußgroß. Über die ganze Schnittfäche der Lungen verstreut findet sich eine Unmenge stecknadelkopfgroßer, braunroter Knötchen, die sich um die kleinen Bronchien zu entwickeln scheinen. Lymphdrüsen des Lungenhylus frei von Herderkrankungen. Auf der Trachealschleimbant finden sich 4 rundlich-ovale infiltrierte Flecken, die in der Transversalrichtung gerichtet sind. In den Bronchien sieht man ähnliche Herde wie in der Trachea. Auf der Magenschleimhaut finden sich 13 schwarzgefärbte Knoten. Auf der Schleimhaut des Darmes finden sich vom Pylorus bis zum After 28 hirsekorn- bis haselnußgroße, rundlich-ovale, der Darmachse entlang gerichtete Knoten. Die größeren Hesde sind im Zentrum ulzeriert. Mesenterialdrüsen intakt. Im Kruraldreieck finden sich große Drüsenkonglomerate. Dieselben finden sich auch in der Bauchböhle um die AA. iliaca externa und communis. Die einzelnen Drüsen haben Bohnengröße erreicht und sind mit dem umgebenden Gewebe fest verwachsen. Auf dem Durchschnitt erkennt man in der Drüsensubstanz rotbraune Herde eingestreut.

Im Übrigen: Schwielige Aortitis, leichte Hypertrophie des linken Herzventrikels, akute parenchymatöse Nephritis, außerdem zahlreiche Steine im r. Nierenbecken. Auf Einschnitten der Skrotalhaut sieht man zwischen der $\mathrm{T}$. dartos und der $\mathrm{T}$. vaginalis eine phlegmonös-jauchige Infiltration: in den nach Gram gefärbten Ausstrichpräparateu des Eiters konnte man massenhafte Streptokokkenketten nachweisen.

Fall 4. Z. M., 74 J. alt, Witwer, Sattlermeister aus Parma.

Dieser Fall ist von Pelagatti 1905 eingebend beschrieben worden und ich verweise für die Einzelnheiten auf die diesbezügliche Publikation. Aus der dort angegebenen Krankengeschichte entnehme ich in Folgendem das Wichtigste: Dem Ausbruch der Hautkrankheit ging ein apoplektiscber Insult mit vorübergehendem Verlust der Motilität linkerseits voraus. Das Hautleiden begann 1910 und zwar an den betroffenen linken Extremitäten; 10 Monate später wurde die rechte Seite befallen. Im Jahre 1903 neuer Schlaganfall mit nachfolgender dauernder Lähmung linkerseits. Nachher machte die Krankheit schnelle Fortschritte.

Pat. wurde am 2\%./VII. 1905 von der Klinik ungeheilt entlassen und trat dann in andere Krankenanstalten ein, so daß wir ihn aus dem Auge verloren. Im Juli 1909 habe ich zufälligerweise die Gelegenheit gehabt, den Patienten in der biesigen städtischen Anstalt für unheilbare Kranke wieder zu treffen. Der kurz vor dem Tode des Patienten erhobene Befund (25./VII. 1909) ist folgender:

Mittelgroßes, stark abgemagertes, sehr elend aussehendes Individuum. Die Beweglichkeit der Extremitäten der linken Seite ist gänzlich aufgehoben. An dem ödematös angeschwollenen Skrotum und am Kreuzbein handtellergroßer Dekubitus. Hochgradige periphere und zentrale Arteriosklerose. Bei der Untersuchung der $\mathrm{Haut}$ findet man über die 
ganze Körperoberfläche zerstreute Flecke und Knoten; es mögen über $100 \mathrm{Krankheitsherde,} \mathrm{große} \mathrm{und} \mathrm{kleine,} \mathrm{vorbanden} \mathrm{gewesen} \mathrm{sein.} \mathrm{Hier}$ seien nur die aufälligsten Veränderungen erwähnt: An der Stirne, fast in der Mitte, findet sich ein linsengroßer, infiltrierter Fleck; auf dem freien Rande des oberen Augenlides des l. Auges findet sich ein gestielter, maiskorngroßer Knoten von rosiger Farbe mit eingesprengten punktförmigen Blutungen: weitere mehr oder weniger große Herde finden sich am Stamme und zwar auf dem l. Akromion und in der Regio hypogastrica, links von der Medianlinie. Die Penishaut und die Glans penis sind mit Flecken und Knötchen besät. Das $\mathrm{Skr}$ otum ist kolossal vergrößert und weist ein ausgedehntes, dunkelbraunrotes, unscharf begrenztes Infiltrat auf. Die Ober-und Unterarme, insbesondere links, weisen zahllose Flecken und Knötchen auf; viele Effloreszenzen sind von einem grüngelblichen Hof umgeben. Auch di e $\mathrm{Hände}$ sind stark befallen, hier wieder am meisten die linke Hand. Letztere zeigt sich steif gebogen gegen den Unterarm, die Finger sind krampfartig in die Handhöhle eingezogen. Die Hant des Handgelenkes und der ganzen Hand ist gleichmäßig geschwollen, stahlgrau verfärbt, auf der Unterlage nicht verschiebbar. Auf dem Kubitalrand des Handgelenkes finden sich nebeneinanderliegend einige halbkugelige, bis erbsengroße Lymphzysten. Untere Extremitäten. Die linke Seite ist wieder am stärksten befallen. Der Fußrücken und die Fußsohle sind polsterartig aufgetrieben; hier und da Knotenbildung. Der 1. Ober- und Unterschenkel zeigen nur eine geringgradige Anschwellung, aber sind mit Flecken und Knötchen in der Weise besät, daß man kaum dazwischen die gesunde Haut sehen kann. Der $\mathrm{r}$. FuB ist nicht angeschwollen und zeigt bloß auf dem Außenrand vereinzelte Knötchen. Auf dem r. Ober- und Unterschenkel finden sich zahlreiche Flecke und Knötchen, aber doch bedeutend weniger wie auf der linken Seite. Bei Besichtigung der Mundschleimhaut sieht man eine bohnengroße Geschwulst auf dem harten Gaumen in der Nähe der 1. oberen Molarzähne.

Verlauf 28./VII. 1909: Dekubitus stärker geworden. Septisches Fieber. Stuhl und Urin werden ins Bett gelassen. Am 1./V1II. 1909 trat Pneumonie auf. 3./VIII. 1909 Exitus.

Bei der Obduktion (14 Stunden nach dem Tode ausgeführt) fanden wir Sarkomberde in den Lungen, in Magen und Darm, in der Leber und in den um die Aa. femoralis und iliaca ext. gelegenen Lymphdrüsen. In den Lungen finden sich, wie beim Falle 3, sowohl größere Knoten wie auch eine Anzahl stecknadelkopfgroßer, im Parenchym verstreuter lnötchen. Es sei nur noch erwähnt, daß einige Partien der größeren Sarkomknoten der Lungen verkalkt sind. In der Magenschleimbaut finden sich 3 , in dem Dünndarm 13, im Kolon 4 Herde. In der Leber finden sich auf der oberen Fläche des r. Lappens, in der Nähe des hinteren Randes, 2 bläulich gefärble, eingesunkene Flecke. Der eine ist hanfkorngroß, der andere erreicht die Größe eines Einmarkstückes. Auf Durchschnitten entsprechen diese Flecke rund- 
lichen, dunkelroten, schwammig aussehenden Knoten des Leberparenchyms. Um die Aa. femoralis und iliaca ext. finden sich voluminöse Lymphdrüsenkonglomerate. Auf dem Durchschnitt ist die Drüsensubstanz fleckweise braunrot verfärbt. - Im Übrigen: In beiden Unterlappen der Lungen konfluierende lubuläre Pneumonie, braune Atrophie des Herz: muskels, zystische Entartung der r. Niere.

Fall 5. V. R., 38 J. alt, verheiratet, Bauer aus Calestano (Parma).

Wir hatten Gelegenheit, den Fat. zum erstenmal im Februar 1909 in der medizinischen Abteilung des städtischen Krankenhauses zu Parma zu untersuchen, wo er wegen einer chronischen Bronchioalveolitis beider Lungenspitzen in Behandlung war.

Status (17./V. 1909): Mittelgroßer Mann von regelmäßigem Knochenbau, in heruntergekommenem Ernährungszustand. Die Hautkrankheit, an welcher Pat. leidet, begann vor etwa einem Jahre und ist zur Zeit auf den Händen, auf dem r. Fuß und auf den Genitalorganen lokalisiert. Die Mundschleimhaut ist frei von Erscheinungen.

Auf dem r. Handrü cken findet sich eine diffuse, unscharf begrenzte, polsterartige Anschwellung von bleigrauer Farbe und derbelastischer Konsistenz. Auf der $\mathrm{l}$. Hand und auf dem $r$. F a $B$ finden sich ganz ähnliche Veränderungen. Am Penis ist das Frenulum verdickt, verhärtet, bläulich verfärbt. Auf dem $\mathrm{Skrotum}$, in einem Abstand von $1 \mathrm{~cm}$ von der Peniswurzel, in der Medianlinie findet sich ein linsengroßer, infiltrierter Fleck. Im Urin nichts Abnormes. Wassermann negativ.

Es war leider nicht möglich, den Kranken längere Zeit in der klinik zu behalten, weil plötzlich schwere Symptome von Irresein (Nahrungsverweigerung, Stupor) einsetzten, die die sofortige Überführung in eine Anstalt indizierten (21./V. 1909). Laut freundlicher Mitteilung des behandelnden Arztes starb Patient im kachektischen Zustand am 30./IX. 1909. Die Sektion ergab Lungen-und Darmtuberkulose; es wurde kein Sarkomberd der inneren Organe vorgefunden.

Fall 6. M. G., 65 J. alt, verheiratet, Schuster aus Colorno (Parma).

Keine hereditäre Belastung. Pat. erkrankte im 18. Jahre an Pocken. Mit 26 Jahren akquirierte er Gonorrhoe. Vor 2 Jahren litt Pat. an Erysipel des Gesichtes. Sonst keine Krankheit. Potus wird negiert.

Die jetzige Krankheit begann vor ungefähr 10 Jahren. Pat. glaubt den Beginn derselben auf eine Verwundung der mittleren Zehe des 1. Fußes, die er sich bei der Arbeit zuzog, zurückführen zu müssen. Aus der offenen Wunde soll wildes Fleisch herausgewachsen sein, das vom behandelnden Ar/t mit Höllenstein gebrannt warde: die Heilung erforderte eines Monat. Kurz darauf schwoll der ganze $\mathrm{Fub}$ an und es traten hläuliche Flecken und Knötchen auf der Haut auf. Nach einiger Zeit bildeten sich die gleichen Knötchen an dem r. Fuß, später wurden auch die beiden Hände damit befallen.

Status vom 12./I. 1911: Großer, kräftiger Mann in gutem Ernährungszustande. Die Untersuchung der inneren Organe zeigt, außer einem 
geringgradigen Lungenemphysem, normale Verbältnisse. Auf dem Innenrand des linken FuBes zählt man 10-12 teils isoliert liegende, teils konfluierende, zumeist von hyperkeratotischen Schichten bedeckte, bläulich gefärbte Knötchen. In den mittleren Teilen der Fußsohle zeigen sich 3 Knötchen, die die dicke Hornschicht durchgebohrt haben. Auf dem Außenrande und auf den benachbarten Teilen des Fußrückens bis zum Malleolus ext. hinauf, breitet sich eine bleigran gefärbte, zackig kontourierte Infiltrationsplatte aus. Ferner finden sich einige Krankheitsherde auf der Haut über der Kniescheibe. Auf dem rechten $\mathrm{FuB}$ finden sich die gleichen Veränderungen, d. h. isolierte Knötchen und infiltrierte Flecken. mit zackigen Rändern. Die Haut über der r. Kniescheibe ist ebenfalls befallen. Die Leistendrüsen sind nicht geschwollen. An den inneren Teilen des linken Handrückens zeigen sich einige unscharf begrenzte, bläulich gefärbte, infiltrierte Flecke mit einzelnen prominierenden Knötchen. Auf dem rechten $\mathrm{H}$ andrücken finden sich nur 2 erbsengroße Knötchen von verrukösem Aussehen. Die $M$ undsch leim hau t zeigt keine Veränderung. Urinbefund normal. Blutbefund: r. Blutkörperchen 6,000.000, w. 11.975. Wassermann negativ.

\section{Histologische Untersuchungen.}

Die durch Biopsie gewonnenen oder von der Leiche entnommenen Stücke wurden teilweise in Alkohol, teilweise in Z enker scher Flüssigkeit fixiert. Die meisten Stücke wurden in Zelloidin eingebettet; die Paraffineinbettung wurden nur da gewählt, wo es darauf ankam, Serienschnitte anzufertigen.

Die Schnitte wurden mit den üblichen Methoden gefärbt. Sehr gute Resultate erhielt ich bei den Zenkerpräparaten mit einer von Pelagatti $i^{1}$ angegebenen Färbungsmethode. Wir wenden die Methode seit Jahren an und können sie, ihrer Vorzüge halber, aufs wärnste empfehlen. Das Verfahren gestaltet sich folgendermaßen:

$Z$ enkerfixierung. Zelloidineinbettung (Paraffineinbettung gibt weniger gute Resultate). 1. Färben der Schnitte in Hämatein conc. Un na (frisch bereitet) 6-12 Stunden. 2. Abspülen im Wasser. 3. Lithiumkarbonat (gesättigte wässrige Lösung). Wenige Sekunden. 4. Abspülen im Wasser. 5. Wasserblau ( $\mathrm{g}$ in $5 \%$ iger Tanninlösung) 2-5 Min. 6. Abspülen im Wasser. 7. Orange G. oder Helianthin $(1 \mathrm{~g}$ in $5 \%$ iger Tanninlösung) 5-10 Minuten. 8. Abspülen im Wasser. 9. Alkohol, Öl, Balsam. Kerne braun; Protoplasma hellgelb; Kollagen braungelb; Muskelfasern grün. Die Erythrozyten färben sich metachromatisch leuchtend rot und gelangen so schön zur Darstellung, wie bei keiner anderen Methode.

1) Pelagatti, Monatsh. f. prakt. Derm., Bd. XXXVIII, 1904, p. 532. 
Hautveränderungen. Präparat 1. Das Stück stellte klinisch einen stecknadelkopfgroßen Herd auf dem l. Vorderarm dar und wurde durch Biopsie gewonnen (Fall III). Im hist. Präparate finden sich 2 übereinander liegende Knötchen. Das obere ist in den obersten Schichten der Kutis gelegen und ist vom Deckepithel lediglich durch einen dünnen Streifen vom Bindegewebe getrennt; das zweite Knötchen liegt in den mittleren Teilen der Kutis. Das schon bei schwacher Vergrößerung auffälligste Merkmal ist die außerordentlich scharfe Abgrenzung der Kuötchen gegen das umgebende Bindegewebe; an manchen Stellen verdichten sich sogar die kollagenen Bündel um die Knötchen und scheinen eine Art Kapsel zu bilden. Bei starker Vergrößerung erkennt man, daß die Knötchen im Wesentlichen aus gewucherten Blutkapillaren sich zusammensetzen; die neugebildeten Gefäße weisen ein kleines, eben wahrnehmbares Lumen auf, als ob sie aneinandergedrückt wären. Die Gefäßwand ist mit großen, ovalen oder kubischen, häufig in Mitose begriffenen Elementen bekleidet. Zwischen den neugebildeten Kapillaren sieht man rundlich-ovale oder spindelförmige Elemente, die in der Grundsubstanz eingebettet liegen; solche Elemente sind wahrscheinlich als gewucherte Bindegewebszellen autzufassen. Ferner finden sich Zellen von lymphozytärem Typus hie und da im Knötchen verstreut. Sowohl im Bereich des Knötchens wie in dem benachbarten Bindegewebe finden sich groß3e Mengen von extravasiertem Blut. Die aus den Gefäßen ausgetretenen Blutkörperchen sind z. T. gut erhalten, z. T. mehr oder weniger zerfallen; die Pigmentbildung ist schon eingeleitet. Mäßige Zahl von Mastzellen. Keine Plasmazellen.

Wir finden also hauptsächlich eine gut begrenzte, lebhafte Wucherung von Blutkapillaren, der sich auch eine mäbige Wucheruug der benachbarten Bindegewebszellen anschließt; ferner kleinzellige Infiltration und Hämorrhagie.

Präparat 2. Hanfkorngroßer, blauroter, unscharf begrenzter Fleck von dem r. Oberschenkel. Das Stück wurde in Paraffin eingebettet und in Serienschnitte zerlegt. Histologisch: Epidermis in der basalen Schicht stark pigmentiert, aber sonst normal. Im Korium finden sich $5-6$ quergetroffene, zu geräumigen Höhlen erweiterte Blutkapillaren, die von dichtgedrängten r. Blutkörperchen ausgefüllt sind. Die betroffenen Blutgefäße liegen in einiger Entfernung voneinander und gehören, ihrer Lage gemä $B$, dem subpapillaren Netze und den Vasa comunic. an. In Serienschnitten verfolgt, gehen die veränderten Gefäße in normale Blutkapillaren über; die Veränderung, d. h. Erweiterung des GefäBrohres setzt ziemlish plötzlich ein, ist unregelmäßig und nach verschieden langem Verlauf hört sie wieder auf, indem das Gefäß sich wieder verengt. Neben den erweiterten, von Blut gefüllten Gefäßen finden sich stellenweise zusammengedrückte Kapillaren mit dentlich gewuchertem Endothel. Im Gewebe sehen wir hier eine kolossale Blutung; jedoch kann man keine Zerreißung der Gefäßwand feststellen. Große Pigmentanhäufungen. Einkernige Rundzellen und Mastzellen mäßig reichlich; keine Plasmazellen. 


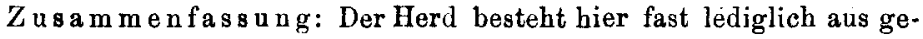
wucherten und erweiterten Kapillaren. Die Veränderungen treten jedoch nicht knötchenweise, wie im Präparat 1, auf, sondern erscheinen verstreut in dem Kutisgewebe. Aus den veränderten Gefäßen treten wahrscheinlich per diapedesin Blutkörperchen massenhaft aus.

Präparat 3. Hirsekorngroßes, bläuliches Knötchen vom Handrücken. Histologisch finden wir, wie in Präparat 1, einen scharf gegen die Umgebung abgegrenzten, stellenweise abgekapselten Herd, der in den oberen Lagen des Koriums gelegen ist und die Epidermis emporwölbt. An der Peripherie des Knötchens finden sich quergetroffene, erweiterte, mit Blut prall gefüllte (refäße mit deutlicher, von abgeplattetem Endothel bekleideter Wand; an einigen wenigen Stellen jst das Lumen der Gefäße noch kaum angedeutet und die Endothelproliferation ist in vollem Gange. Der gröBte Teil des Knötchens bietet folgendes Aussehen: es finden sich Züge von scbönen, spindeligen Zellen, die in verschiedener Richtung verlaufen und quer oder ihrer Länge nach getroffen werden. Selten sind die Spindelzellenbündel kompakt; meistens weichen die einzelnen Zellen auseinander und begrenzen Höhlen und Lakunen, die von dicht aneinanderliegenden r. Blutkörperchen gefüllt sind. An einigen Stellen wird durch diesen Vorgang das ganze Bündel aufgefasert. Zum größeren Teil ist das Blut zwischen den Spindelzellen gut erhalten, zum kleineren Teil ist es in Zerfall begriffen. In der nächsten Umgebung des Herdes finden sich kolossale Mengen von hämatogenem Pigment. Einkernige Rundzellen und Plasmazellen in mäßiger Auzabl.

Ich deutediegeschilderten Befunde in der Weise, daß Kapillarwucherung und -erweiterung bestehen und daneben auch Spindelzellen auftreten. Es kommt nun, wie in den vorigen Präparaten, Hämorrhagie vor, und diese erfolgt, den topographischen Verbältnissen gemä $\beta$, zwischen den Spindelzellen. Das Blut bleibt eine Zeitlang erbalten: dann erfolgt allmählich Zerfall der r. Blutkörperchen und Pigmentbildung.

Präparat 4. Erhabene, blaurote, derbe Infiltrationsplatte aus der r. Leistengegend. Histologisch findet man im Korium Veränderungen mannigfacher Natur. Was die Blutgefäße aubelangt, so weisen einige derselben ein ganz normales Lumen auf; andere sind mächtig erweitert und mit Blut gefüllt. Es gibt ferner Gefäße, die ein erweitertes, blutleeres Lumen mit zusammenfallenden, etwas verwischten Wänden aufweisen, als ob sie in Obliteration begriffen wären; an einem solchen Gefäße konnte ich sehr dentlich eine Zerreißung der Wand feststellen. Die Lymphgefäße sind gewuchert und stellen kolossal erweiterte, von geronnener Lymphe ausgefüllte Spalten dar; hie und da nimmt das Gewebe dadurch ein schwammiges Aussehen an. Um die Blutgefäße findet sich eine dichte kleinzellige Infiltration, die in den Schnitten als Knötchen auftritt und größtenteils aus typischen Plasmazellen besteht. Letztere weisen in großem Maße nekrobiotische Vorgänge auf; das Protoplasma verschwindet, der Kern wird piknotisch und zerfällt schließlich in Chromatinbröckelchen. 
Es finden sich ganze Infiltrationsknötchen, die diesen Veränderungen gleichmäßig anheimfallen. Des Weiteren sehen wir im Gewebe fädige, fibrinöse Massen, die amorphkörnigen Detritus und zerfallende Erythrozyten enthalten. Das Fibrinnetzwerk ist besonders dicht in den Umgebungen der Blutgefäße.

Außer den besprochenen Veränderungen finden sich in den untersten Lagen der Kutis zwei größere, kompakte Herde von Spindelzellen. An den Spindelzellen sind zahlreiche, schöne Mitosen nachzuweisen. Blutkapillaren sind in spärlicher Anzahl vorhanden. Die Abgrenzung der Herde von der Umgebung scheint beim ersten Blick eine scharfe; bei genauerer Betrachtung der Serienschnitte kann man aber feststellen, daB die Spindelzellenzüge hin und wieder mit den Bündeln des Koriums in fester Verbindung stehen und sich direkt in diese fortsetzen. Der Übergang der Spindelzellenzüge in die kollagenen Bündeln geschieht allmählich, in der Weise, daß3 das Bindegewebsbündel nach und nach zellreicher erscheint und schließlich das fertige Kollagen gänzlich verschwindet. Stellenweise scheint diese Umwandlung in den Interstitien zwischen den kollagenen Bündeln zu beginnen. Die Spindelzellenzüge, die auf diese Weise ihren Ursprung genommen haben, bahnen sich in raschem Wachstum den Weg in die Umgebung. Es muß noch gesagt werden, daß man bei Verfolgung der Serienschnitte an eine Stelle kommt, wo ein mächtiges Blutextravasat zwischen den Spindelzellen auftritt. Bemerkenswert ist die Tatsache, daß der Spindelzellenherd, entsprechend dieser Blutung, an Größe abnimmt und sehr bald aufhört, so daß man den Eindruck bekommt, daß die Hämorrhagie den Anstoß zu der Spindelzellenwucherung gegeben hat.

Die wesentlichen Veränderungen sind also zusammengefabt etwa folgende: Veränderungen der Blutgefäße, die z. T. im Abklingen begriffen sind; Wucherung der Lymphgefäße; kleinzellige Infiltration und fibrinöse Ablagerungen im Gewebe; Herde von Spindelzellen in der Tiefe der Kutis.

Präparat 5. Bläulich gefärbte Stelle des Präputium (Fall 3). Mikroskopisch findet man die verschiedensten Veränderungen beieinander. In den mittleren und untersten Teilen der Kutis sehen wir mehr oder weniger abgegrenzte Herdchen von gewucherten Blutkapillaren: ein solcher Herd ist in das Lumen einer tiefen Vene hineingewuchert. Daneben sehen wir ein festes Gefüge von Spindelzellen; die präexistierenden Bindegewebsbündel bleiben inmitten der Spindelzellen noch erbalten und sind sowohl an ihrer Beschaffenheit wie auch an dem Vorhandensein von elastischen Fasern erkennbar. Man sieht ferner in den mittleren und untersten Kutisschichten ausgedehnte Bezirke, wo das Korium sich in ein maschiges Gewebe umgewandelt hat. Die Lakunen sind verschieden breit und zumeist leer. Die Septa bestehen teilweise aus dünnen Bindegewebstrabekeln; an den Stellen, wo die verschiedenen Veränderungen zusammenfließen, werden die Septa entweder von angiomartig erweiterten Blutkapillaren oder gar von Spindelzellen gebildet. Das ganze histologische 
Bild gibt bestechend die Abbildungen von Bernhardt (Arch. f. Derm. u. Syph., Bd. LXIII, Tafel XIII) wieder. Es handelt sich offenbar um eine Neubildung und Erweiterung von Lymphgefäßen. - Zusammenfassend finden wir im Präparate Neubildung von Blutkapillaren, von Lymphgefäßen und von Spindelzellen in bunter Mischung vor.

Lymphdrüsen. In den Fällen 3 und 4 wurden die Lymphknoten der Inguinalgegend und der Fossa iliaca interna mikroskopisch untersucht. Die makroskopisch vergrößerten Drüsen weisen z. T. keine Spur von Herderkrankungen auf, und die Veränderungen beschränken sich auf eine mäßig starke Verdickung des Stromas. Dieselbe steht offenbar in Zusammenhang mit der großen Menge von amorph-körnigem (nach Perls sich färbendem) bämatogenem Pigment, das sich in der Kapsel, in den Lymphsinus und in den peripheren Teilen des Follikel abgelagert findet.

Viele Lymphknoten sind dagegen vom Tumor eingenommen. Das Geschwulstgewebe tritt in den Lymphdrüsen als Züge von Spindelzellen mit feinen Blutkapillaren auf; Bluthöhlen und erweiterte Blutgefäße kommen hier weniger oft vor. Die Follikel und die Follikularstränge werden vom Tumorgewebe verdrängt und gehen allmählich zugrunde. In fortgeschrittenen Stadien ist das eigentliche Lymphgewebe fast gänzlich verschwunden und nun findet man im Geschwalstgewebe kleine Anhäufungen von Lymphozyten, die offenbar die Reste der verschwundenen Follikel darstellen. Die Lymphbahnen und die Sinusräume sind z. T. verödet, z. T. sind sie von einer krümligen, große, runde sich nicht mehr gut färbende Zellen enthaltenden Masse ausgefüllt. Die Drüsenkapsel zeigt sich stellenweise vom Tumor durchwachsen: in dem umgebenden Fettgewebe finden sich ausgedehnte Tumorherde, die die erkrankten Drüsen zusammenschmelzen. Die Arterien, Venen und Nerven der Fossa iliaca interna liegen in solchen Tumorenmassen eingebettet.

Magen und Darm. Bei der Untersuchung eines han fkorng r o $B$ en Knötchens der Pylorusschleimbaut (Fall 2) fanden wir folgende Veränderungen: Der Tumor ist in der Tunica submucosa lokalisiert. Die darüberziehende Schleimhaut ist emporgewölbt, aber sonst normal: die Schicht der muskulären Ringfasern ist infolge der Kompression verdünnt, die Schicht der Längsfasern und der peritoneale Überzug sind unverändert. Die Geschwulst besteht im Wesentlichen aus Zügen von Spindelzellen, die in den Interstitien der (etwas vermehrten) kollagenen Bündel der Submukosa verlaufen: $z$ wischen den einzelnen Spindelzellen ist eine zarte, fibrilläre Substanz nachweisbar, die in die fertigen kollagenen Bündel der Umgebung äbergeht. Die Blutgefäße des Tumors sind sebr spärlich; es finden sich aber, sowohl im Bereich des Knötchens, wie in dessen Umgebung kolossale Mengen von hämatogenem Pigment, die auf eine vorangegangene Hämorrhagie hindeuten. Die durch das Knötchen ziehenden Arterien und Venen weisen eine hochgradige Intimawucherung mit Verengerung des Lumens auf.

Befund an einemein markstü ckgroßen, im Zentrumulzerierten Knoten des Ileums: zwischen den kollagenen Balken der Submukosa Arrh. f. Dermat. u. Syph. Bit. CIX. 
finden sich, wie im obigen Präparat, wirr durcheinandergehende Bündel von Spindelzellen. Bindegewebe deutlich vermehrt, reichliche Rundzellen. Die Geschwulstzellen infiltrieren die Schichten der muskulären Ring- und Längsfasern und reichen bis an die Subserosa heran. Große Mengen von körnigem Pigment. - Die Schleimhaut des Darmes fehlt vollkommen, entsprechend den ulzerierten Partien. Das Geschwulstgewebe liegt an der Oberfäche des Darmes und zerfällt nekrotisch. Die Blutgefäße sind an der freien Oberfläche durch Thromben verschlossen.

In anderen Knötchen des Darmes, die ich untersucht habe, waren weite Blutgefäße und Höhlen vorhanden; dieselben machten den größeren Teil des Tumors aus. Die Spindelzellen traten wieder in den Hintergrund und ordneten sich zuweilen den erweiterten Gefäßen entlang.

Lungen. (Fälle 3 und 4.) In den Lungen fesseln zunächst unsere Aufmerksamkeit die kleinsten, im Lungenparenchym eingestreuten, stecknadelkopfgroßen Tumoren, die schon im Sektionsprotokolle herrorgehoben wurden. An Serienschnitten kann man nachweisen, dab diese Herdchen mit großer Regelmäßigkeit um die kleinen Bronchien und die die Bronchien begleitenden Äste der A.pulmonalis sich entwickeln. Primär im Alveolarparenchym entstandene Knötchen habe ich nicht gefunden.

Wenn wir die ersten Anfänge der Tumorentwicklung aufsuchen wollen, so sehen wir, $\mathrm{da} B$ das peribronchiale Gewebe stel:enweise zellreicher erscheint als normal, und auBerdem weite, dünnwandige, mit $r$. Blutkörperchen vollgestopfte Räume enthält; in den benachbarten Lungenalveolen finden sich zuweilen schon in diesen frühen Stadien ausgetretene r. Blutkörperchen. - In fortgeschritteneren Stadien kommen um die Bronchienwand herum die neugebildeten Kapillaren immer mehr zum Vorschein; es erscheinen hie und da kleine Züge von Spindelzellen, und schließlich findet man das für diese Geschwulstart durchaus charakteristische, netzartige Gewebe, dessen Maschen mit Blut gefüllt sind. Die elastisch-muskulöse Wand der Arterie bleibt unverändert, dagegen greift der Tumor relativ bald auf die Bronchialwand über, letztere wird allmählich vom Geschwulstgewebe infiltriert. In der nächsten Umgebung der Knötchen spielen sich am Lungevparenchym verschiedene Veränderungen ab. Es kommt in den Alveolen des Nachbargewebes zu Blutextravasation, zwischen den ausgetretenen r. Blatkörperchen finden sich in den Alveolen Rundzellen und abgestoßene Alveolarepithelien, die körniges Pigment enthalten. An manchen Stellen ist die Desquamation der Epithelien so hochgradig, daß man von einer umschriebenen desquamativen Pneumonie sprechen könnte.

Die weitere Entwicklung des Tumors können wir in den größeren Knoten, die offenbar seit längerer Zeit bestehen, genau studieren. In einem haselnußgroßen Knoten kann man Folgendes nachweisen: Im Bereich des Knotens ist in der Lunge keine Spur von normalem Alveolenparenchym mehr vorhanden. Man sieht fast überall ein dichtes, festes Gewebe von nahezu gleichmäßigem Aussehen. Das Gewebe besteht im Wesentlichen aus spindelförmigen Zellen, die sich in Zügen anordnen. Der proto- 
plasmatische Körper der Spindelzellen geht ohne Grenzen in eine fibrilläre Zwischensubstanz über. Man hat den Eindruck einer Bindegewebsneubildung, die in fibröser Umwandlung begriffen ist. Das Gewebe ist nicht besonders gefäßreich. Spärliche Rundzellen. - Bei guter Elastinfärbung zeigen sich die elastischen Fasern im Bereich des Tumors in ihrer Kontinuität unterbrochen und liegen hier und da regellos eingestreut. An vielen Stellen ist aber das elastische Netz noch gut erbalten, und die Alveolenzeichnung tritt darum bei Elastinfärbung scharf hervor. Hier kann man sehr schön studieren, wie die Spindelzellenzüge in die Alveolen eindringen; die histologischen Bilder erinnern an diejenigen, die man bei den Organisationsvorgängen des Exsudates nach Lungenentzündungen (sog. Karnifikation der Lunge) zu sehen bekommt. - Die durch den Knoten ziebenden Blutgefäße weisen eine hochgradige Intimawucherung auf. Der Prozeß befällt sowohl die Venen, wie die Arterien, letztere sind allerdings in geringerem $\mathrm{MaBe}$ betroffen. Erwähnenswert ist noch der Befund von Gängen und Kanälen, die eine dicke Wand und ein rundlich-ovales, häufig infolge der Kompression spaltförmig verengtes Lumen aufweisen. Sie stellen offenbar die kleinen Bronchien des betroffenen Lungenbezirkes dar. Ihr Lumen ist gewöhnlich von abgestoßenen uud zusammengebackenen Epithelzellon ausgcfüllt.

Leber. (Fall 4.) Das mikroskopische Aussehen des Herdes in der Leber zeigt sich verschieden im Zentrum and in der Peripherie. In den zentralen Teilen besteht die Geschwulst im wesentlichen aus einem grobmaschigen Netzwerk. Es finden sich hier rundliche oder länglich-ovale, von Endothel begrenzte Räume, die von dichtgedrängten, gut erhaltenen r. Blutkörperchen ausgefüllt sind; daneben findet man Räume, die zerfallenes Blut und Reste von Leberzellen enthalten. Fs steht auBer Zweifel, daß letztere alveolenartige Räume durch die Zerstörung der Leberläppchen und das Übrigbleiben des interlobulären Bindegewebes zustande kommen. Im Zentrum des Knotens ist von Tumorzellen fast nichts nachzuweisen.

Ander Peripherie des Tunors ist das Gewebe viel dichter. Infolge des von den zentralen Bluthöhlen ausgeübten Druckes rücken an der Peripherie die interlobulären Balken aneinander, so daß die Grenzen zwischen Tumor und Lebergewebe ziemlich scharf sind und durch einen (an manchen Stellen unterbrochenen) Bindegewebsstreifen gebildet werden. Die Verdickung des Bindegewebes gegen das gesunde Lebergewebe könnte beim ersten Blick eine Geschwulstkapsel vortäuschen. Wir baben es hier wohl mit Gewebe der Glissonschen Kapsel zu tun; eine eigentliche Kapsel der Geschwulst, die Aurch eine reaktive Entzündung der Umgebung entstanden ist, scheint nicht vorzuliegen. - Bei genauer Betrachtung sehen wir, dab das Tumorgewebe an vielen Stellen in die Umgebung hineinwächst.

Die Infiltrierung spielt sich ausschließlich in der nächsten Nachbarschaft des Knotens ab; eine Verstreuung der Geschwulstelemente in einige Entfernung ist nicht vorhanden. Zwischen den Leberzellensträngen 
der Umgebung erscheinen bald erweiterte, von Blut strotzend gefüllte Kapillaren, bald Spindelzellenzüge, die von der Peripherie des Läppchens gegen das Zentrum zu vordringen. Im weiteren Verlauf kommt es zur Neubildung von Bindegewebsfasern, die Leberzellen werden auseinandergedrängt und isoliert. So finden sich Leberzellenstränge oder auch vereinzelte Leberelemente, in verschiedenen Stadien des Zerfalles, vom übrigen Parenchym getrennt und im Tumorgewebe eingebettet. - Die Leberzellen, auch weitentfernt vom Knoten, enthalten in ihrem Protoplasna reichliche Pigmentkörnchen, die sich durch die Perlsche Reaktion zum großen Teil als $\mathbf{H a ̈ m o s i d e r i n ~ e r w e i s e n . ~}$

Genitalien. (Fall 3.) In den frontal durch die amputierte Glans gerichteten Schnitten sieht man, daB das dunkelbraunrot aussehende Geschwulstgewebe die Eichel in ihrer ganzen Dicke gleichmäßig infiltriert und auch das vordere Ende des Corpus cavernosum urethrae ergriffen hat. Nur in den hinteren Partien der Glans sind noch hier und da kleine Inseln von gesundem Gewebe übrig geblieben. Die Corpora cavernosa penis sind frei von Veränderungen.

Mikroskopisch kann man folgendes nachweisen: Die Oberhaut der Glans ist auf weite Strecken verdickt mit gewucherten Epithelleisten; stellenweise dagegen erscheint die Epidermis, infolge des Druckes des unterliegenden Tumors, hochgradig verdünnt. In der Nähe des Frenulum fehlt die Oberhaut vollständig; das Geschwulstgewebe liegt frei zu Tage und ist reichlich mit gelapptkernigen Leukozyten durchzogen. - Unter der Epidermis, zwischen dieser und der Faserhaut findet sich eine dicke Schicht von neoplastischem Gewebe, die mantelartig das eigentliche Schwellgewebe der Eichel in ihrem ganzen Umfang umgibt. Hier ist das histologische Bild ein sehr buntes. An manchen Stellen (es sind das die wenigsten) findet man Veränderungen, die denjenigen gleichen, die in beginnenden Effloreszenzen der Haut beschrieben worden sind, d. h. man sieht eine ausgesprochene Wucherung von Blutkapillaren. - Am bäu. figsten findet man aber doch weite Bluträume und interstitielle Haemorrhagien. Das Gewebe ist in ein feines Netzwerk umgewandelt, das dünne, fadenförmige, zuweilen vollkommen kernlose Septa aufweist; die Maschen sind von dichtgedrängten, z. T. zerfallenden $r$. Blutkörperchen ansgefüllt. Hier und da sind spärliche Haufen und Züge von Spindelzellen zu sehen, die aufgefasert werden und in die Septa übergehen. - Lymphozyten und Plasmazellen sind mehr oder weniger überall eingestreut, stellenweise gruppieren sich diese Elemente zu kleinen Knötchen. - Das eigentliche Schwellgewebe der Glans ist von der Neubildung diffus durchwachsen. Im vorderen Fünftel ist die Infiltration derart fortgeschritten, daß man kaum Reste des ursprünglichen Gewebes nachweisen kann; das neugebildete Gewebe zeigt sich hier links stärker entwickelt als rechts, die Harnoöhre dementsprechend nach rechts verschoben. Nach hinten zu ist das Eichelgewebe inselförmig noch erhalten und behält seine gröbere Zeichnung. An diesen Stellen gelingt es leicht, die fortschreitende Durchwucherung der Glans durch die Geschwulstmassen zu verfolgen. 
Besonders interessant gestaltet sich im histologischen Bilde die Durchwachsung der weiten Venen der Glans durch die Geschwalst. Wir sehen, daB die Wand allmählich von pathologischem Gewebe ersetzt wirä. Die Geschwulst ist hier gewöhnlich von angiomatösem Bau, d. b. bestehi aus nebeneinander liegenden, enorm erweiterten Kapillaren. Solche Blathöhlen springen in das Lumen der Vene stark vor und sind vom Veneninhalt lediglich durch eine dünne Endothelschicht getrennt. Schließlich führt der Prozeß zur vollkommenen Obliteration des Venenlumens. Das Endothel der Venen verhält sich ganz passiv; an ihm sind keine Zeichen von Wucherung wahrzunehmen. Die elastischen Fasern der Venenwand bleiben ziemlich lange erhalten. - Wir finden weiter im kavernösen Gewebe Haufen von Spindelzellen, Kaötchen kleinzeliiger Infiltration und kolossale Blutungen. - Die Urethra mündet, wie oben erwähnt, in einer grubigen, ulzerierten Vertiefung der Eichelspitze. Wenn man in den Schnitten die Harnröhre von vorne nach hinten verfolgt, findet man, da $B$ der Kanal einige Millimeter vor dem Meatus verengt ist und nach rechts verschoben wird, so daB eine winkelige Striktur zustande kommt. Dann hat die Urethra die normale Richtung und Weite.

\section{Klinischer Teil.}

Wir glauben von der klinischen Beschreibung der Krankheitsherde der Haut, sowie ihrer Umwandlungen und Nebenerscheinungen absehen zu können, da es nur zu Wiederholung von bereits Bekanntem führen würde. Die folgenden Ausführungen beschränken sich auf einige bemerkenswerte Einzelheiten, die sich aus der eigenen Beobachtung und aus der kritischen Durcharbeitung der Literatur ergeben haben.

Wir möchten zunächst auf die geographische Ausbreitung der Krankheit hinweisen. Bei der Durchsicht der einschlägigen Literatur findet man, daß eine ganze Reihe von Fällen von russischen Autoren beschrieben worden sind; besonders in Polen scheint die Krankheit häufig zu sein. Viele Fälle stammen auch aus den an Rußland angrenzenden Provinzen Österreich-Ungarns. In Italien kommt das Leiden verhältnismäßig häufig vor; man bedenke nur, daß über 100 Fälle von $\mathrm{Kaposischem} \mathrm{Sarkom} \mathrm{von} \mathrm{italienischen} \mathrm{Autoren}$ beschrieben worden sind. In den nördlichen und westlichen Ländern Europas nimmt die Häufigkeit des Leidens bedeutend ab. Die in Deutschland gemachten Beobachtungen betrafen zum 
großen Teil eingewanderte Russen oder Kranke, die aus den östlichen Provinzen stammten. Auch in Frankreich scheint das Leiden zu den großen Seltenheiten zu gehören; aus der französischen Literatur sind mir nur einige wenige Fälle von Perrin und 1 Fall von Balzer und Pois ot bekannt. Von englischen Autoreu sind meines Wissens 8 Fälle beschrieben worden, davon betrafen 3 (1 Fall von Pringle und $\mathrm{Mac}$ kenzie, 1 Fall von Weber und Daser, 1 Fall ron Sequeira) eingewanderte polnische Juden. In Nord-Amerika sind, meines Wissens, etwa 15 Fälle von Ka p o s i schem Sarkom beschrieben worden; fïnfmal darunter findet man die genaue Angabe, daß die Patienten russischer Herkunft waren; jedoch in seltenen Fällen scheint das Leiden auch bei eingeborenen Amerikanern vorzukommen (Fälle von $\mathrm{H}$ ardaway, von $\mathrm{Jak}$ son, von Stevens, von Hartzell). Diese aus der Literatur herausgegriffenen Angaben, die wohl auf Vollständigkeit keinen Anspruch machen können, genügen, um zu beweisen, daß das Kaposische Sarkom einen sehr bestimmten Vorzug für gewisse Länder hat. ${ }^{1}$ )

Bernhardt (1902) hat darauf aufmerksam gemacht, daß die semitische Rasse eine besondere Neigung zu dem Kaposischen Sarkom zu haben scheint. Die Bernhardtschen Beobachtungen waren sehr bestechend: Im jüdischen Krankenhaus zu Warschau sei die Kranhheit gar nicht selten (12 Fälle in J Jahren), im St. Lazarus Hospital dagegen, wo fast ausschließlich das slawische

1) Um diese Angaben zu vervollständigen, habe ich mich an mehrere, in verschiedenen Ländern Europas tätige Dermatologen gewandt. Die mir bisher freundlichst zugesandten Notizen bestätigen die ausgesprochene Bevorzugung der Krankheit für gewisse Länder und das Verschontbleiben anderer Länder sehr entschieden. In Deutschland (Berlin, H a mb arg und Leipzig) sei die Krankheit fast ausschließlich bei Auswärtigen (zumeist Russen) gesehen worden; ebenfalls in der Schweiz (Bern und Lausanne). In Kopenhagen wurde bisher kein Fall bemerkt. In Stockholm wurden während der letzten 15 Jahre 7 Fälle beobachtet, im A msterdam während der letzten 10 Jahro 7 Fälle, in Brüssel in den letzten 15 Jahren 3-4 Fälle. In Frankreich, soweit die mir aus Paris, Bordeaux und Toulouse eingelaufenen Nachrichten lauten, komme die Krankheit so gut wie gar nie vor. Aus Madrid wurden mir 3 Fälle bekannt gemacht. 
Element zur Behandlung kommt, sei seit mehr als 20 Jahren kein einziger Fall ron S. i. beobachtet worden. Ich glaube aber, daß diese, seither aufgenommene und in allen Lehrbüchern und Spezialarbeiten wiederkehrende Angabe, daß die Juden in besonderer Weise von der Krankheit heimgesucht werden, einer Kritik bedari. Man muß doch bedenken, daß in jenen Gegenden, aus welchen ein großer Prozentsatz der Kranken stammt, sehr viele Juden ansässig sind, und zumeist den niedrigeren Klassen angehören; darin kann der relativ größere Prozentsatz der Krankheitsfälle bei Juden seine Erklärung finden. In anderen Ländern, wo die numerischen und sozialen Verhältnisse der semitischen Rasse umgekehrt $\mathrm{zu}$ den in Polen und Rußland vorhandenen sich gestalten, wird in bezug auf die $\mathrm{K}$ a pos i sche Krankheit gerade das Gegenteil beobachtet, so z. B. in Italien, das zu den von der Erkrankung am schwersten heimgesuchten Ländern zählt, ist, meines Wissens, kein einziger Fall von S.i. m. H. bei Juden bekannt geworden. Um eine bessere Auskunft zu erhalten, wandte ich mich an Prof. De Amicis (Neapel), dem ja bekanntlich eine große Erfahrung in diesen Dingen zur Seite steht (schคn 1897 konnte er über 50 selbst beobachtete Fälle von S. i. berichten); er teilte mir brieflich mit, daß kein einziges Mal in seinen Fällen die Erkrankung Juden hetraf. Ich glaube also nicht fehlzugehen, wenn ich die angegebene Disposition der semitischen Rasse für das Kaposische Sarkom für nicht ganz bewiesen halte.

Es hat sich noch aus der Gesamtheit der Beobachtungen ergeben, daß die Krankheit bis auf wenige Ausnahmen Leute zu befallen pflegt, die anstrengenden Berufen nachgehen und unter schlechten hygienischen Verhältnissen leben. Es werden vorzugsweise $M a ̈ n n e r$ betroffen. In der von mir zusammengestellten Literatur finden sich nur 8 Fälle von sicherem S. i. m. H. die sich auf Frauen bezichen (Fälle von Köbner, Haras, Metscherski, Pringle, Pelagatti, W. Pick, Halkin, Kempf. ${ }^{1}$ ) Die Krankheit kommt am häufigsten bei Erwachsenen vor.

1) Die älteren Fälle von Taylor (1875) und Wigglesworth (1876) (zit. von Sequeira, Brit. Journ. of Dermat. 1901), die ebenfalls Frauen betrafen, sind dabei nicht inbegriffen. Auch die Fälle von 1 a u- 
Zuweilen (jedoch nicht gerade häufig) ist das Vorhandensein einer lokalen Disposition zur Erkrankung nachzuweisen. Ein schönes Beispiel in dieser Beziehung stellt mein Fall 3 dar, bei welchem die ersten krankhaften Erscheinungen zunächst an den linken paralytischen Extremitäten auftraten und erst später sich auf die andere Seite verbreiteten; auch nach jahrelangem Bestehen des Leidens zeigte sich ein merklicher Unterschied zwischen den beiden Seiten, indem die linken, gelähmten Extremitäten mit Flecken und Knoten bedeckt waren, während die rechte Seite verhältnismäBig verschont blieb. Somit erschien das Vorhandensein einer größeren Disposition der gelähmten Seite zur Erkrankung in diesem Falle zweifellos. Um diese Disposition zu erklären, können wir uns, m. E., mit der Annahme einer Herabsetzung der Trophik, bzw. der normalen Gewebswiderstände in den gelähmten Teilen begniigen.

Bezüglich der Disposition wurde von W. Pick behauptet. daß Störungen der Lymphzirkulation die lokale Disposition für die Entwicklung des Kaposischen Sarkomes abgeben können. $\mathrm{Zu}$ dieser Ansicht kam Pick auf Grund von 2 Fällen von S. i., in welchen das Leiden als Elephantiasis lymphangiectatica begann und der Übergang der Lymphzysten mit klarem Inhalt zu solchen mit hämorrhagischem Inhalt und dann weiter zu weichen und derben Tumoren beobachtet werden konnte. Die Annahme Picks ist an und für sich nicht zu verwerfen, sie kann ja möglicherweise zutreffend sein; auch der von mir beobachtete, oben angeführte Fall würde diese Erklärung zulassen, denn es findet sich bekanntlich in den gelähmten Partien eine verminderte Strömungsgeschwindigkeit des Blutkreises. - Die Behauptung Picks erscheint mir aber in mancher Hinsicht nicht ganz einwandsfrei. Wir müssen nämlich unterscheiden zwischen dem, was der Neubildung selbst gehört und dem, was ihr Wachstum begünstigt und als prädisponierende Ursache aufzufassen ist. In den meisten Fällen von S. i. findet man die präzise Angabe, daB die ödematöse Schwellung den Krankheitserscheinungen kurz vorangegangen ist und sehr bald die blauen chez und Schattück habe ich nicht mitgerechnet, weil sie mir nicht. ganz einwandsfrei erscheinen. 
Flecken und Knoten hinzugekommen sind; in schon ausgeprägten Fällen pflegt das Ödem der erkrankten Partien kaum zu fehlen. Nun wäre m. E. ein solcher ödematöser Zustand eher an die Seite der übrigen Krankheitssymptome zu stellen, als zu den prädisponierenden Ursachen zu rechnen. Die Lymphzysten, die Pick in seinen Fällen beobachtet hat, würden ebenfalls, nach meiner Ansicht, $\mathrm{zu}$ der schon eingesetzten Erkrankung gehören; und in der Tat sind diese Bildungen von den Autoren vielfach als neugebildete Lymphgefäße aufgefaßt, und an die Seite der für die Erkrankung charakteristischen Blutkapillarneubildung gestellt worden. Wenn endlich Pick zur Stütze seiner Behauptung den Umstand anführt, daß die Tumorbildung an den peripheren Teilen beginnt, an welchen die Lymphzirkulation ohnedies behindert ist, so wäre dagegen einzuwenden, daß auch andere Argumente die eigenartige Lokalisation des Leidens zu erklären vermögen.

Gehen wir nun zur Krankheit selbst über, so müssen wir hervorheben, daß in einer gauzen Anzahl von Fällen, besonders in denen, wo die Kranken frühzeitig zur Untersuchung gelangten, festgestellt worden ist, daß die Krankheit mit einem einzigen Herd beginnt. Es war Philippson, der zuerst auf diesen Umstand hingewiesen und dementsprechend die ursprïngliche Schilderung Kaposis modifiziert hat. ${ }^{1}$ ) Es hat sich nun ein reiches Material gesammelt, das diese Tatsache über alle Zweifel stellt. Auber den Fällen Philippsons und den von ihm zitierten Fällen $S \mathrm{chw}$ i mmers und Bernhard ts seien folgende Beobachtungen erwähnt: ein Fall von Havas (erste Erscheinung: erbsengroßes Knötchen auf der Beugeseite der r. Handwurzel), ein Fall von Weber und Daser (Anfang der Krankheit an der r. Fußsohle mit einer gestielten, aus einer Wunde herausgewachsenen Geschwulst), ein Fall von W. Pick (Anfang der Krankheit an der Haut des r. Schienbein-

1) Übrigens war dieser Umstand schon Perrin 1886 bekannt, der das Kaposische Sarkom je nach seinem Beginn in 2 Arten teilte: „Debut par extrémités ou par tumeur isolée en un point quelconque et suivie rapidement de l'extension aux extrémités." $\mathrm{Zu}$ den letzteren rechnet Perrin einen Fall von Tanturri, einen Fall von De Amicis und einen Fall von Hardaway. 
knöchels), ein Fall von De I,uca (Anfang der Krankheit mit einem einzigen Knoten auf dem r. Fußrücken), ein Fall ron Radaeli (IX. Fall: Anfang der Krankheit an dem Septum narium mit einem maiskorngroßen Knötchen), ein Fall von Got theil (erste Erscheinung: kleines, bläuliches Knötchen an der Innenseite des $r$. Unterschenkels) und viele andere.

Des weiteren verdient unsere Beachtung die Tatsache, daß sich in manchen Fällen die Angabe findet, daß dem A u sbruch der Krankheit ein Trauma vorangegangen ist. In einem Falle von W. Pick erschien der erste Herd nach einem Schlag mit einem Stock auf die Gegend des r. Schienbeinknöchels; Lieberthal beobachtete einen Fall, in welchem im Anschluß an eine Verletzung Eiterung auftrat; die Inzision nötig machte, ein Jahr später an derselben Stelle Schwellung und kleine Knoten; Weber und Daser sahen eine sarkomatöse, botryomykosisähnliche Geschwulst im Anschluß an einen Nadelstich an der r. Fußsohle auftreten; Pelagatti berichtet, daß in einem Falle die ersten Sarkomherde um eine Operationsnarbe sich entwickelten; in einem von De Luca veröffentlichten Falle erschienen die ersten Knoten am r. Fußrücken, kurz nachden Patient eine schwere Verletzung des r. Unterschenkels (unteres Drittel) mit Knochenbruch sich zugezogen hatte; der Patient Stravinos verwundete sich beim Abziehen des Felles eines geschlachteten, rotzkranken Pferdes mit dem Messer am l. Fußrücken, worauf langdauernde Eiterung eintrat; nach einiger Zeit brennendes Gefühl und Erscheinung kleiner, blauroter Knötchen in der nächsten Umgebung der Wunde; beim Patienten $\mathrm{Zumbuschs}$ traten die ersten Sarkomherde auf, nachdem ein Pferd dem Patienten auf den l. Fuß getreten war und zwar anderthalb Jahre später an derselben Stelle. Es sind das, wie es scheint, selar genaue Beobachtungen, denen wir nicht jeden Wert absprechen können, wie man auch den Einfluß des Traumas auf den Ausbruch der Erkrankung auffassen möge.

Außer den gewöhnlichen Lokalisation en an den Extremitäten fanden sich fast in allen unseren Fällen mehr oder weniger zahlreiche Krankheitsherde an den Genitalien; im Falle 3 war die Glans penis derart befallen, daß wegen der starken 
Urinbeschwerden die Amputation rorgenommen werden mußte. Die Mundschleimhaut, die ron einigen Autoren zu den häufigsten Lokalisationen gezählt wird, war nur in der Hälfte unserer Fälle befallen. - Ich erinnere noch bezüglich der Lokalisation, daß wir im Falle 2 die Anordnung der Herde einer subkutanen Vene entlang beobachten konnten.

Es ist längst bekannt, daß die Tumoren eine große Neigung zu Hämorrhagien haben; letztere treten klinisch durch die grüngelbliche Verfärbung der Haut rings um die Knoten zum Vorschein. Es kann aber gelegentlich, während des Krankheitsverlaufs, auch das Auftreten von Hämorrhagien in gesunder Haut beobachtet werden, worauf zuweilen die Entwicklung von Tumorherden an der Stelle der Blutung folgt. Philippson berichtet, daß in einem seiner Fälle täglich über die ganze Körperoberfläche verteilt, hämorrhagische Flecke erschienen, aus denen z. T. in der folgenden Zeit Knoten sich entwickelten. Ich konnte eine ähnliche Beobachtung im Falle 3 machen; freilich hatte hier die Erscheinung eine mehr regionäre Ausbreitung, indem sie sich auf die Ober- und Unterschenkel beschränkte. Es traten daselbst gelbliche unscharf begrenzte Flecken auf; dementsprechend fühlte sich die Haut beim Falten leicht ödematös an. In den folgenden Wochen bildete sich zuweilen an der Stelle der Blutung eine knotige Verdickung der Haut aus, die schließlich den anderen Krankheitsherden ähnlich wurde. - Laut mündlicher Mitteilung konnte auch Pelagatti bei einem Sarkomkranken, der längere Zeit in der von ihm geleiteten dermatologischen Klinik zu Sassari (Sardinien) lag, gleiches beobachten; es traten schubweise gelbliche Flecken auf an der Innenseite der Oberschenkel, am Abdomen und auf der Skrotalhaut mit mäBigem Ödem und darauffolgender Entwicklung von kutanen Infiltraten. -- Man könnte nun zur Erklärung dieser Erscheinung sich denken, daß die Haut, in der die Hämorrhagie stattfindet, nur scheinbar gesund sei, d. h. daß die Blutung von einem minimalen, klinisch nicht wahrnehmbaren Sarkomherd stamme: deshalb sei der Vorgang den gewöhnlichen, vorhin erwähnten Erscheinungen (Blutung in einem Sarkomherd) gleichzustellen. Die anatomische Untersuchung frischer Blutungsherde spricht aber dagegen: ich fand, 
wie Philippson, eine, an den Grenzen zwischen Kutis und Subkutis gelegene Vene, die ron roten, gut erhaltenen Blutkörperchen umgeben war und offenbar den Sitz der Hämorrhagie darstellte; sonst keine Veränderung. Man ist also gezwungen, den klinischen Befund im Sinne einer hämatogenen Entstehung vom Krankheitsherde in die Haut zu deuten.

Was die Entwicklung der einzelnen Sarkomherde anbetrifft, so ist ihr Wachstum zumeist ein begrenztes, ja sie können sich unter Umständen nach einiger Zeit vollkommen involvieren. Es kommen aber, wenn auch selten, Fälle vor, wo das Sarkomgewebe in die Tiefe weiter unter die Haut wuchert und auf wichtigere Organe übergreift. So war in einem meiner Fälle die ganze Glans penis in eine Sarkommasse umgewandelt. Bei der bäufigen Lokalisation der Knoten an den Händen und Füßen kann es durch Tiefenwachstum zu mehr oder weniger ausgedehnter Zerstörung der Sehnen und der Phalangealknochen kommen. Scholtz, Bernhardt, Halle haben je über einen derartigen Fall berichtet und die Knochenveränderungen durch Röntgenstrahlen oder durch die anatomische Untersuchung der amputierteu Teile festgestellt. Neuerdings beschreibt $\mathrm{Zum}$ b u s ch einen Fall von nultiplem idiop. Hautsarkom, bei welchem in den Knochen des l. Fußes bei Röntgendurchleuchtung mehrere scharf begrenzte, strahlendurchlässige Stellen, offenbar Sarkomherde, nachgewiesen wurden; auffallender Weise hatten in diesem Falle die Veränderungen der Knochen eine Lokalisation, die derjenigen der bedeckenden Haut nicht entsprach, sie dürften also nicht bloB eine Fortsetzung des Hautprozesses per contiguitatem, sondern eine richtige Metastase darstellen. Bei meinen sarkomkranken waren Veränderungen der Knochen, soweit dieselben sich durch Röntgen feststellen ließen, nicht vorhanden.

Schon in seiner ersten grundlegendeu Veröffentlichung hat Kaposi angegeben, daß das Leiden sich nicht nur in der Haut, sondern auch in den inneren Organen lokalisieren kann.

Es ist nicht zu bestimmen, in welcher genauen Periode des Krankheitsverlaufes die inneren Herde auftreten; angesichts der Tatsache, daß in den frühzeitig zur Sektion gelangten Fällen von S. i. nur Veränderungen der Haut und keine der inneren Organe nachgewiesen wurden, ist aber mit Sicherheit anzu- 
nehmen, daß die Erkrankung der inneren Organe derjenigen der Haut folgt, und wahrscheinlich nach einiger Zeit auftritt, nachdem die Hautaffektion besteht. - Zuweilen gelingt es, die inneren Herde intra vitam festzustellen. So weisen z. B. blutige Diarrhöen bei solchen Sarkomkranken aut Metastasen des Darmtraktus hin. Kudis ch hat bei einem Falle die Vergrößerung der Leber, Ikterus, Diarrhöe beobachtet und als Ursache Sarkommetastasen in der Leber und Darm angenommen. R i s s o m demonstrierte in der Berl. derm. Gesellschaft einen Sarkomkranken, der blutigen Auswurf hatte; durch die Röntgenstrahlen wurde in der $r$. Thoraxhälfte ein nußgroßer Schatten nachgewiesen; böchstwahrscheinlich handelte es sich um Sarkommetastasen der Lungen. Auch wir konnten im Falle 3 aus den Ergebnissen der physikalischen Untersuchung mit einer gewissen Wahrscheinlichkeit Lungenmetastasen vermuten: im Sputum wurde nie größere Blutbeimischung wahrgenommen, es fanden sich mikroskopisch nur vereinzeite $r$. Blutkörperchen und viele Herzfehlerzellen.

Durch das Auftreten innerer Metastasen wird der Zustand des Kranken bedeutend erschwert. Der Exitus wird durch die sarkomatöse Affektion lebenswichtiger Organe, oder durch die früher oder später einsetzende Kachexie, oder durch interkurrente Krankheiten herbeigeführt. Unter letzteren ist an erster Stelle das Erysipel zu nennen, an welchem eine ganze Anzahl von Sarkomkranken zu Grunde geht. Einer meiner Patienten starb an Lungen- und Darmtuberkulose.

Die gesamte Krankheitsdauer ist sehr wechselnd. Kaposi hatte sie zunächst auf 2-3 Jahre berechnet, spätere Beobachtungen lehrten aber, daß das Leiden im Durchschnitt sich über 8-10 Jahre hinzieht; in einigen Fällen betrug die Dauer sogar 20 und mehr Jahre. In folgender Tabelle habe ich die Fälle zusammengestellt, die seit 1900 in der dermatologischen Klinik zu Parma zur Beobachtung kamen: für die meisten Fälle haben wir durch Nachforschungen die gesamte Dauer der Krankheit bestimmen können (siehe Tabelle).

Therapeutisch wurde bei der Kaposischen Dermatose seit jeher die Arsenmedikation am wirksamsten mittelst Injektionen der Fowlerschen Lösung oder einer Lösung von 


\begin{tabular}{|c|c|c|c|c|c|c|c|c|c|c|c|}
\hline$\sqrt{0}$ & $\equiv \ddot{0}$ & 0 & $\infty$ & $\rightarrow$ & 0 & $\sigma$ & $\oplus$ & $\omega$ & $N$ & 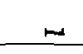 & Zahl \\
\hline 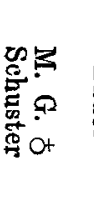 & 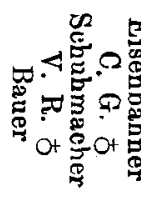 & & 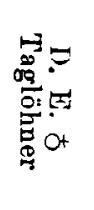 & : & 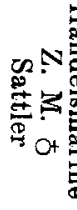 & 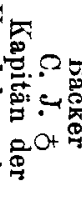 & & 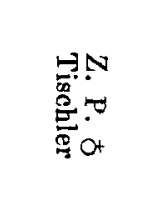 & 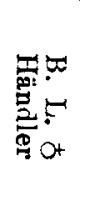 & 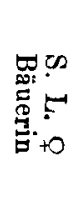 & 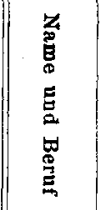 \\
\hline gr & $\underset{్}{\mathbb{J}}$ & $\stackrel{A}{A}$ & 忿 & $\stackrel{8}{\infty}$ & $\stackrel{8}{\Theta}$ & \& & $\exists$ & $\stackrel{\mathscr{A}}{\AA}$ & $\mathscr{\infty}$ & $\Rightarrow$ & 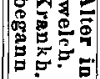 \\
\hline 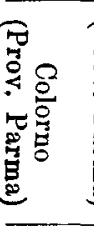 & 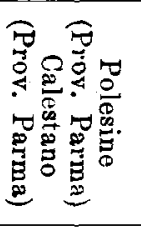 & 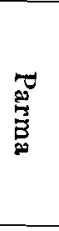 & 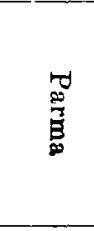 & 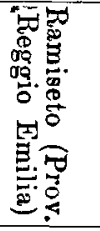 & 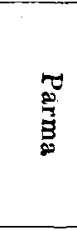 & & 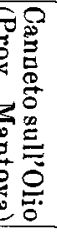 & 尝 & 总 & 党 & 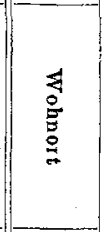 \\
\hline 1 & | & 1 & 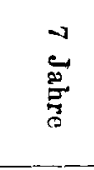 & 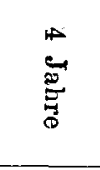 & $\begin{array}{l}0 \\
0 \\
0 \\
0 \\
0 \\
0\end{array}$ & 1 & $\begin{array}{l}N \\
\stackrel{N}{c} \\
\stackrel{5}{\sigma}\end{array}$ & $\begin{array}{l}10 \\
10 \\
40 \\
0 \\
0 \\
0\end{array}$ & $\begin{array}{l}\tilde{0} \\
0 \\
0 \\
5 \\
5 \\
0\end{array}$ & 1 & 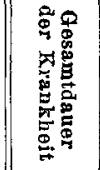 \\
\hline 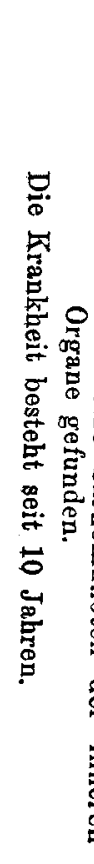 & 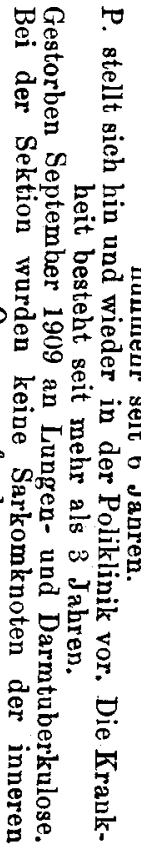 & 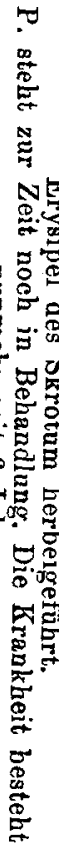 & 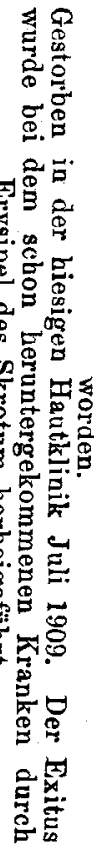 & 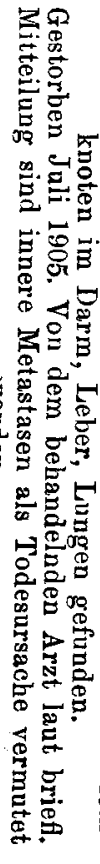 & 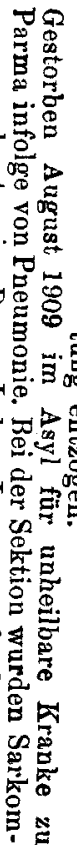 & 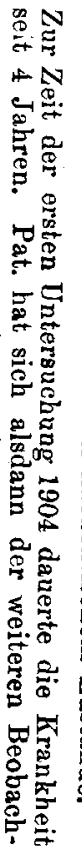 & 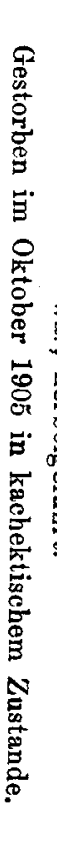 & 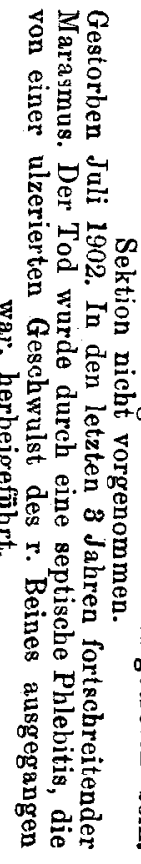 & 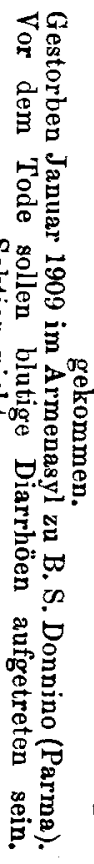 & 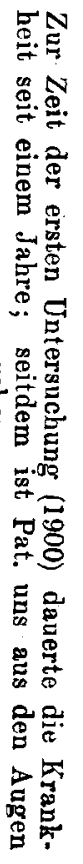 & $\begin{array}{l}> \\
z \\
5 \\
0 \\
7 \\
7 \\
\Rightarrow \\
8 \\
08 \\
0 \\
y\end{array}$ \\
\hline
\end{tabular}


Natr. arsenicos. empfollen. In Bezug auf die Wirkung des Arsens drückt sich De Amicis in der Weise aus, daß man von therapeutischen Gesichtspunkten ausgehend, die Hautsarkomatose in 2 Klassen teilen könnte; in die eine kämen diejenigen Fälle, bei denen das Arsen Erfolg hat, in die zweite die anderen. Dies ist gewissermaßen richtig, weil die Fälle von S. i. auf Arsen sehr rerschieden reagieren. Die Fälle, die durch Arsen zur vollkommenen Heilung gebracht wurden, gehören jedenfalls $z u$ den großen Seltenheiten; soweit ich aus der Literatur ersehe, finden sich nur die Fälle von $K \ddot{b} b n e r, S c h a t t \ddot{u} c k$ und $D e$ A micis ${ }^{1}$ ) angefübrt. Mehr oder weniger ausgeprägte und anhaltende Besserungen nach Arsendarreichung sind viel häufiger rerzeichnet worden. - Aber andererseits hatte das Arsen häufig genug keinen Erfolg. So konnte ich in allen meinen Fälien, bis auf einen, keinen nennenswerten Einfluß von der Arsenbehandlung wahrnehmen; besonders im Falle 3 konnte der fortschreitende Gang der Krankheit trotz ausgiebiger, bis zur Grenze der Toleranz fortgesetzter Arsendarreichung nicht im geringsten angehalten werden. Bloß bei einem Kranken (Fall 1) hatte es den Anschein, als ob während der Arsenbehandlung, wenn auch nicht eine Besserung, so doch ein Stillstand in dem Wachstum der Herde erreicht worden wäre; denn, nach dem Aussetzen der Arseneinspritzungen, zeigte sich in wenigen Wochen ein merkliches Wachsen der Knoten.

Immerhin muß man bei der Beurteilung des Behandlungserfolges mit Arsen bei der Kaposischen Dermatose berücksichtigen, daß die Krankheitsherde an und für sich eine spontane Tendenz zur Involvirung haben. Da diese Tendenz von Fall zu Fall in großen Grenzen variiert, so ist jedesmal der Anteil des Arsens an der Besserung kritisch zu bestimmen. So beobachtete ich beispielsweise im Falle 2 eine Besserung schon nach 5 Injektionen von Natr. arsen. à 0.005 ; dann entzog

1) $\mathrm{Zu}$ beachten ist, daß diese wenigen durch Arsen geheilten Fälle von S. i. etwas Eigentümliches an sich hatten. Die Zugehörigkeit des Falles Schattücks zu dem Kaposischen Sarkom kann aus guten Gründen bezweifelt werden, wie es übrigens auch Perrin tut. Die Fälle Köbners und De Amicis betrafen auffallend junge (resp. 8 und 15 Jahre alte) Patienten; außerdem ist der Fall Köbners nicht ganz typisch. 
sich der Kranke der Behandlung und doch dauerte der eingeleitete Rückgang der Effloreszenzen noch monatelang weiter. Ich habe nun manche Bedenken, die Zurückbildung der Herde in diesem Falle auf die ganz minimale Quantität des eingeführten Arsens zurückzuführen; es will mir wahrscheinlicher erscheinen, dab die Besserungfviel mehr in der gutartigen Form der Krankheit zu suchen sei.

Wie die Wirkungsweise des Arsens bei dem $\mathrm{K}$ a p o si schen Sarkom zu erklären ist, ist noch eine offenstehende Frage. Ein gewisser Teil der Wirkung des Mittels fällt sicher auf die günstige Beeinflussung des Allgemeinzustandes und auf die Steigerung der natürlichen Widerstandskräfte des Organismus. Es ist aber auch leicht möglich, daß das eingenommene Arsen auf die Krankheitsherde selbst eine lokale Wirkung ausübt; dies wird wahrscheinlich gemacht durch die Untersuchungen von Winkler, der, anläßlich einer Mitteilung über die Beeinflussung der Psoriasis vulg. durch die Arsentherapie, kundgibt, daß es ihm gelungen ist, in einem Falle von S. i. durch lokale elektrolytische Arseneinführung blaurote, stark elevierte Knoten des Fußrückens zum Abblassen und Abflachen zu bringen, und zwar beschränkte sich die Arsenwirkung lediglich auf die behandelten Stellen. Ich hatte nun Gelegenheit, beim Patienten 1 den Versuch Winklers einer Nachprüfung zu unterziehen, und konnte tatsächlich an den Stellen, wo die Arsenlösung elektrolytisch eingeführt wurde, ein deutliches Blässer- und Kleinerwerden der Knoten wahrnehmen; diese Veränderungen der behandelten Partien beruhten offenbar auf Vasokonstriktion, denn es ist ja bekannt (Weidenfeld), daß die lokale Applikation von Arsenlösungen auf die Haut einen kontrahierenden Einfluß ausübt. Der Versuch Winklers konnte aber insofern nicht bestätigt werden, als die Vasokonstriktion nicht dauernd, und speziell kein wirklicher Rückgang der Herden selbst nach vielen Sitzungen nachzuweisen war, wie ich durch exakte Messungen der erkrankten Teile feststellte. Trotzdem halte ich das Vorhandensein einer lokalen Wirkung des Arsens auf die Krankheitsherde prinzipiell für nicht ausgeschlossen; möglicherweise verhalten sich in diesen Versuchen (wie bezüglich der internen Arsendarreichung) die einzelnen Fälle sehr verschieden voneinander. 
Außer der medikamentösen Arsendarreichung sind bei dem Ka p osischen Sarkom auch andere therapeutische Maßnahmen am Platze. Sehr gute Resultate gibt des öfteren die Anwendung der Röntgenstrahlen; die bestrahlten Tumoren pflegen mit Hinterlassung von bräunlichen Flecken zurückzugehen. Somit kann ein befriedigendes funktionelles Resultat, beispielweise der Gebrauch der schwer affizierten Hände und Füße, erreicht werden : ferner wird durch Röntgen eine nicht zu unterschätzende Linderung der subjektiven Beschwerden erzielt. Radaeli berichtet in der letzten Zeit über gute Erfolge selbst durch die Finsenstrahlen. - Natürlich kann von Heilung durch diese Prozeduren nicht die Rede sein.

Nun komme ich zu einer, mit wenigen Ausnahmen übersehenen, aber jedoch m. E. bezüglich der Therapie sehr wichtigen Frage. Da, wie oben angeführt, das S. i. m. h. unter Umständen mit einem einzigen Herde beginnt, so denkt man sich unwillkürlich, ob das Leiden durch frühzeitige Exzision des Primärherdes nicht zu heilen wäre. In einer Reihe von Fällen (Hardaway, Schwimmer, Gottheil, Weber und Daser) ist dies auch versucht worden, jedoch ohne Erfolg, denn nach kurzer oder längerer Zeit sind weitere Krankheitserscheinungen aufgetreten. Andererseits finden wir aber auch wieder Fälle, wo der vermutliche Primärherd des S. i. ausgeschnitten und keine Rezidive sichtbar wurden; ich sage ausdrücklich "vermutlich“, weil wir leider nicht in der Lage sind, entscheiden zu können, ob es sich hier um einen initialen Herd von Kaposischem Sarkom oder ein sog. Botryomykom handelte. $\mathrm{Zu}$ dieser Kategorie unerklärter Fälle zählen z. B. einige Fälle von Philippson, die er als beginnendes $\mathrm{K}$ aposisches Sarkom auffaßt; ferner eine gewisse Anzahl (nicht alle!) der unter der Bezeichnung „sog. menschliche Botryomykose" beschriebenen Fälle, beispielsweise diejenigen von $K$ ü t $t \mathbf{n}$ er, einige Fälle von $\left.\mathrm{mir}^{1}\right)$ u. a. Darauf komme ich weiter unten zu sprechen.

Was die Differentialdiagnose des S. i. m. H. betrifft, so wissen wir, daß Verwechselungen mit Syphilis (Gummiknoten), Lepra tuberosa, Lupus vulgaris und verschiedenen

1) Dalla Favera. Beiträge zur Kenntnis der sog. menschlichen Botryomykose. Unn a-Festschrift. Bd. II.

Areh, f. Dermat. n. Syph, Bd. CIX. 
Hauttumoren rorkommen können; hierüber sei auf die Literatur verwiesen. Ich beschränke mich nur aus eigener Erfahrung auf die Möglichkeit einer Verwechslung mit Sklerodermie hinzuweisen. Im Falle 1 erinnerten die eigentümlichen Veränderungen der Hände sehr an Sklerodermie. Die Haut, insbesondere die der Finger, war in diffuser und gleichmäßiger Weise verdickt uud verhärtet, auf der Unterlage unverschieblich, von schmutziggrauer leicht zyanotischer Farbe; auch die infiltrierten, sehr harten Plaques (Knotenbildung bestand in der ersten Zeit nicht), die auf den Armen und Beinen verstreut sich fanden, sprachen ja nicht gegen die Diagnose von Sklerodermie, die in der Tat von fachmännischer Seite gestellt worden war. Allerdings konnten die Beobachtungen des weiteren Verlaufes und das Auftreten neuer Herde auf den richtigen Weg hinweisen.

Des weiteren muß man die Differentialdiagnose zwischen den initialen Herden des S. i. m. H. und den sog. Botryomykomen in Erwägung ziehen. Schon Weber und Daser 1905 haben, bezüglich einer interessanten Beobachtung, diesen Gegenstand angedeutet: seither ist diese Tatsache von Kreibich und dann ron $\mathrm{mir}$ in Betracht gezogen worden.

Den entsprechenden Passus der Arbeit $W$ eb ers und $D$ a s ers erlaube ich mir wörtlich anzuführen: „The present illness commenced about three years before, when he chanced to wound the sole of his rigth foot with a nail. A pedunculated growth, about the size of a cherry, arose from the wound. This description reminds one of the strawberry-like granulation tumours sometimes growing from small wounds or ulcers on the fingers, which have been termed "Botryomycosis" or rather "botryomycomata" because at one time they were supposed to be caused by the botryomyces. The growth was removed hy a doctor. Afterwards small bluish nodules developed from time to time on the feet and legs ....4

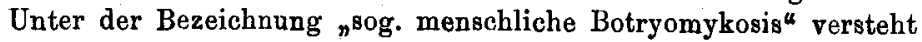
man bekanntlich kleine, gestielte, meistens an den unbedeckten Körperteilen lokalisierte Geschwälste des Menschen. Der Name stammt von Poncet und Dor 1897, die die Affektion als eine der Botryomykose der Tiere identische Erkrankung auffaßten. Obwohl heute die Theorie P on c et und Dors kaum mehr Anhänger findet, wird doch die Bezeichnung nmenschl. Botryomykose ", um die genannten Bildungen zu benennen, noch weiter beibehalten. Höchstwahrscheinlich handelt es sich dabei nicht um eine einheitliche Affektion, wie aus den histologischeu Untersuchungen zu ersehen ist. Manchmal bestehen diese Fleischwarzen aus gewöhnlichem Granulationsgewebe und ist ihnen nicht mehr Bedeutung als den wuchernden 
Wundgranulationen beizumessen. In einer Reihe von Fällen dagegen weicht der histologische Bau von demjenigen der Granulationen ab und nähert sich den geschwulstmäßigen Bildungen; und zwar ähnelt dasselbe dem Bau des Kaposischen Sarkomes in so hohem Maße, daß eine Unterscheidung auf Grund des histologischen Befunde, kaum möglich ist. Die Ursache der sogenannten Botryomykose ist unbekannt.

Die Differentialdiagnose $z$ wischen den sogenannten Botryomykomen und beginnenden, mehr lokalisierten Formen des S. i. kann unter Umständen großen Schwierigkeiten begegnen, um so mehr da die eventuell zur Klärung der Diagnose herangezogene mikroskopische Untersuchung keine sicheren Aufschlüsse liefert.

\section{Histologischer Teil.}

Wenn wir nun uns der Histologie des S. i. m. h. zuwenden wollen, so sind wir uns wohl bewußt, daß wir ein vielbestrittenes Gebiet betreten. Die anatomische Grundlage der Affektion ist eine sehr bestimmte, denn bei klinisch sicheren Fällen haben fast alle Forscher die gleichen Befunde verzeichnet. Trotzdem gehen die Ansichten in der Deutung der Histogenese und des Wesens des Prozesses weit auseinander.

Aus der Betrachtung unserer Präparate ergibt sich zunächst, daß eine Neubildung von Blutkapillaren stattfindet. In manchen Herden (vgl. Präparat 1 und 2) bilden die gewucherten Blutkapillaren den wesentlichen Bestandteil. Der Prozeß kann in der Haut entweder von den Kapillaren des subpapillaren Netzes oder von der Vasa comunic., oder von dem tiefen Netz seinen Ursprung nehmen. Es werden bloß die Gefäße kapillarer Natur befallen; die Arterien und Venen weisen gar keine Veränderung dieser Art auf. An den betroffenen Kapillaren kann man zuweilen sehr deutlich die Wucherung der Endothelzellen beobachten. Die Wucherung des Endothels hat in der Regel die Bildung neuer Kapillaren zur Folge; nur selten findet man lumenlose Endothelsprossen, aus $3-4$ Zellen bestehend, in direkter Verbindung mit der Kapillarwand. - Die Neubildung von Blutkapillaren geht gewöhnlich mit einer Erweiterung derselben einher. Ob nur die neugebildeten Kapillaren oder auch, wenigstens zum kleinen Teil, die schon vorhandenen es sind, die erweitert erscheinen, kann man nicht mit Genauigkeit ent- 
scheiden. - Eine nahezu konstante Begleiterscheinung der Kapillarneubildung und -erweiterung ist das mehr oder weniger reichliche Austreten der r. Blutkörperchen aus den Blutgefäßen in das umgebende Gewebe. Dies erfolgt, zum großen Teil, par diapedesin, was durch die Stase und die Veränderungen der Wand begünstigt wird; nur an wenigen Präparaten gelang es mir eine Zerreißung der Wand, d. h. ein Bersten der prallgefüllten Kapillaren nachzuweisen. Die ins Gewebe ausgetretenen r. Blutkörperchen zerfallen und es kommt zur Pigmentbildung. Derartige Veränderungen der Blutgefäße haben wir in keinem der von uns untersuchten Krankheitsherde vermißt; allerdings kamen sie in sehr verschiedener Ausbildung vor, indem die Neubildung und Erweiterung der Kapillaren zuweilen ausgeprägt waren, mitunter aber auch nur noch sich Pigment fand, das auf vorangegangene Blutungen, d. h. auf Veränderungen der Blutgefäße hindeutete.

Außer der besprochenen Blutkapillarneubildung kommt auch Neubildung und Erweiterung ron Lymphbahnen, d.h. die Bildung von Lymphangiomen vor. P hil i p p s o n hat 3 Fälle solcher Art beschrieben, Sellei konnte das in 1 Falle, W. $\mathrm{Pick}$ in 2 bemerkenswerten Fällen feststellen. In einem Falle von Bernhardt waren die Veränderungen der Lymphbahnen so vorherrschend, daß dieser Autor sich berechtigt glaubte, einen Untertypus des Kaposischen Sarkoms aufzustellen und die Bezeichnung S. i. m. en plaques pigmentosum et lymphangiectodes für seinen Fall vorzuschlagen. In den genannten Fällen saßen die Veränderungen der Lymphbahnen an den Lieblingssitzen der Erkrankung, d. h. an den Händen und Füßen und imponierten auch klinisch durch ihr eigenartiges Aussehen als oberflächliche eindrückbare Zysten mit klarem, serösem Inhalt. Ich habe auch zweimal Gelegenheit gehabt, derartige Veränderungen zu beobachten; beide Male saßen die Lymphzysten auf der linken Hand (vgl. die Krankengeschichten der Fälle 1 und 4). Ich bin ferner auf Grund der eigenen Beobachtung zu der Meinung gekommen, daß Veränderungen leichteren Grades des Lymphsystems klinisch übersehen, vielleicht auch nicht konstatiert werden können (z. B. wenn die gewucherten Lymphgefäße in den tieferen Hautschichten gelagert sind, oder wenn 
sie von etwa vorhandenen Blutgefäßektasien verschleiert werden) und daß solche Veränderungen der Lymphbahnen im Grunde genommen weit häufiger vorkommen, als es bisher angenommen worden ist. So fanden wir bei der histologischen Untersuchung einer Stelle der Vorhaut des Falles 3 (vgl. Präparat 5), an welcher klinisch bloß eine Verdickung und bläuliche Verfärbung zu verzeichnen waren, die untere Koriumschichte in ein eigenartiges, schwammiges Gewebe umgewandelt, das offenbar aus neugebildeten und erweiterten Lymphkanälen bestand. Äbnliches ließ sich bei der Untersuchung einer derben Infiltrationsplatte der $r$. Leistengegend des Falles 2 nachweisen. Freilich sind bezüglich der Wucherungen der Lymphgefäße die histologischen Verhältnisse nicht so einfach zu deuten, wie bei der Blutkapillarneubildung und bei beginnenden, wenig ausgesprochenen Stadien kann man schwer ein Urteil abgeben, ob ein einfaches Ödem und Erweiterung der Lymphgefäbe oder auch eine Neubildung derselben vorliege.

Der dritte Bestandteil des Kaposischen Sarkoms sind die Spindelzellen. Das sind schöne bipolare Zellen mit ovalem, mäßig chromatinreichem Kerne und pyroninophilem Protoplasma, die sich in Zügen anordnen und sich kreuzen und verflechten. Die Spindelzellen sind sehr bäufig zu treffen, sind aber in sehr verschiedenem Maße in den Herden vorhanden, denn, wie oben erörtert, finden sich Tumoren, die fast lediglich aus neugebildeten Blutgefäßen sich zusammensetzen.

Über die Herkunft der Spindelzellen ist man noch nicht einig. Viele Autoren haben versucht die Neubildung der Spindelzellen in irgend eine Beziehung zu der oben erörterten Neubildung der Blutkapillaren zu bringen. Am weitesten sind in dieser Richtung diejenigen gegangen, die die Spindelzellen von den Endothelien der Blutgefäße abgeleitet haben.

Diese Ansicht stützt sich im wesentlichen auf die morphologische Ähnlichkeit der Spindelzellen mit den Endothelien und auf die Beobachtung, daß zwischen den Spindelzellen sehr häufig Blutkörperchen auftreten. Solche Gründe scheinen uns nicht stichhaltig zu sein. So sind die morphologischen Charaktere an und für sich nicht maßgebend, denn man weiß, daß, während der pathologischen Wucherung, die Bindegewebszellen 
und namentlich die der Gefäßwand anliegenden Zellen eine große Ähnlichkeit mit den Endothelien aufweisen können. Ferner ist sehr wohl möglich, daß das Vorhandensein von r. Blutkörperchen zwischen den Spindelzellen hin und wieder einfach durch Hämorrhagie zu stande kommt (vgl. Präparat 3). Gegen die endotheliale Abstammung der Spindelzellen scheint uns der folgende Umstand zu sprechen: Es wäre zu erwarten, falls die spindeligen Elemente aus Endothelzellen herrorgehen, dab an den Stellen, wo die Endothelproliferation besonders rege erscheint, auch die Spindelzellen in gleichem Maße auttreten. Das ist aber gerade nicht der Fall; denn wir treffen Herde (vgl.Präparat 1), wo eine lebhafte Wucherung der Endothelien im Gange ist und Spindelzellenzüge dagegen sich nicht nachweisen lassen. Andererseits treffen wir mächtige Züge von Spindelzellen, die, wie aus den vielen Karyokinesen zu ersehen ist, in lebhaftem Wachstum begriffen sind (vgl. Präparat 4) und sehr spärliche Blutgefäße aufweisen. Endothelwucherung und Spindelzellenbildung zeigen sich also von einander unabhängig.

Andere Autoren haben angenommen, daß die spindeligen Elemente des K.schen Sarkoms aus den Perithelien der Blutgefäße hervorgehen. Es wird hier leider übersehen, daß die Bezeichnung "Perithel" zur Zeit einem anatomisch und pathologisch gut definierten Begriff noch nicht entspricht und es werden bloß topographische Verhältnisse für hinreichend und maßgebend gehalten. Das kann nur die Verwirrung steigern; denn wir wissen einmal nicht, ob die bei Sarcoma idiopathicum wuchernden "Perithelien" besondere Zellen sind, die die perivaskulären Lymphräume bekleiden und demnach den Endothelien gleichwertig sind, oder ob die adventitiellen (vielleicht den Bindegewebszellen identischen) Belegzellen der Kapillaren gemeint werden. Ich habe bei S. i. in manchen Präparaten Spindelzellen gesehen, die sich an der Außenseite von Blutkapillaren entwickelten und stellenweise sogar eine Art Scheide bildeten. Auch die Bündel von Spindelzellen, die wirr durcheinandergehen, enthalten zuweilen in der Mitte ein feines Blutgefäß und dies scheint die Richtung der Spindelzellen zu bestimmen. Meiner Meinung nach sind es solche Bilder gewesen, 
die den Anstoß zu dem Begriff Peritheliom gegeben haben. Ich muß aber gleich bemerken, $\mathrm{da}$ ß dieser Befund keineswegs so konstant ist, um eine Verallgemeinerung in bezug auf die Geschwulsthistogenese zu erlauben. Ferner ist zu betonen, daß die perivaskuläre Anordnung der neugebildeten Zellen uns nicht ohne weiteres berechtigt, von Peritheliom (oder Angiosarcoma peritheliale) zu sprechen. Es ist doch bekannt, daß in jedem Sarkom die Geschwulstzellen die Neigung baben, die jungen Gefäße zu umgeben, weil sie hier die beste Ernährung finden; auch bei den normalen Wachstumvorgängen des Bindegewebes, so z. B. in den Granulationen, finden sich Kapillargefäße, die von einem Mantel junger Gewebszellen scheidenartig umschlossen sind.

Auf Grund meiner eigenen Untersuchungen wäre ich geneigt, die Spindelzellen des K.schen Sarkoms, wenigstens zum großen Teil, als Abkömmlinge der Bindegewebszellen aufzufassen. Diese Abstammung kann direkt verfolgt werden, indem es an geeigneten Stellen gelingt, die allmähliche Fortsetzung der Spindelzellenzüge in die kollagenen Bündel des Koriums zu verfolgen (vgl. Präparat 4). An solchen Stellen scheint es, daß die ersten Anfänge der Wucherung in den Interstitien der Koriumbündel vorkommen, was doch verständlich ist, wenn man den Reichtum dieser Stellen an Zellen und Gefäßen berücksichtigt. Als wichtiger Beweis für die bindegewebige Abstammung der Spindelzellen ist auch die Beobachtung anzuführen, daß die Spindelzellen fähig sind kollagene Substanz zu bilden. Es ist uns leicht gelungen, durch elektive Kollagenfärbungen (Mallory, v. Gieson, Unn a sche Methoden) ganz junge Fäserchen nachzuweisen, die aus dem spindeligen Zellenleib entspringen. Die weiteren Umwandlungen der Spindelzellen, die wir weiter unter sehen werden, sprechen ebenfalls für die Richtigkeit unserer Auffassung.

Es sei endlich der kleinzelligen Infiltration gedacht. Dieselbe besteht aus Lymphozyten und Plasmazellen, die bald vereinzelt, bald in größeren Anhäufungen sich finden. Die Verteilung dieser Elemente in den Tumorherden gestaltet sich nach meinen Untersuchungen derart, daß die einkernigen Rundzellen in weit überwiegendem Maße sich da finden, wo die be- 
schriebenen Veränderungen der Blut- oder der Lymphbahnen vorhanden sind; dagegen sind sie verhältnismäßig spärlich in den Spindelzellenherden, namentlich in jenen älteren Herden, die in fibröser Umwandlung begriffen sind. Sichere Übergänge der Plasmazellen zu Spindelzellen, wie W. Pick angibt, babe ich nicht gesehen. Auf den Ursprung der einkernigen Elemente will ich nicht eingehen, dena dies interessiert uns nur nebensächlich; es steht ja heute fest, $\mathrm{da} B$ einerseits Lymphozyten aus den Gefäßen ins Gewebe auswandern und daß, andererseits, in der Adrentitia der Gefäße zellige Elemente (Marchands leukozytoide Zellen) vorkommen, deren Proliferation mononukleäre, den Lymphozyten sehr ähnliche Elemente liefert. Bezüglich der Genese der Plasmazellen dürfte wohl kein Zweifel bestehen, daß dieselben von lymphozytenartigen Elementen und zwar ganz besonders von den leukozytoiden Zellen des Bindegewebes ihren Ursprung nehmen. Mehr von Wichtigkeit ist die Frage nach der Bedeutung der kleinzelligen Infiltration bei diesem Krankheitsprozeß. Die Annahme, daß die Lymphozyten und Plasmazellenanhäufungen lediglich im Sinne einer entzündlichen, reaktiven Proliferation des normalen Gewebes gegen die Geschwulsteinwucherung zu erklären seien, scheint mir wenig Wahrscheinlichkeit für sich zu haben, aus vielen Gründen, u. a. weil die Verteilung der kleinzelligen Infiltration äußerst unregelmäßig ist und oft in keinem Verhältnis zu den eigentlichen Geschwulstherden gebracht werden kann, ferner angesichts der bekannten Tatsache, daß bei den Sarkomen (um ein solches würde es sich handeln, falls man die Geschwulstnatur unserer Krankheit annimmt) die Plasmazellen sehr spärlich auftreten. Die kleinzellige Infiltration könnte m. E. zum Teil als eine indirekte Folge der die Krankheitsherde begleitenden Veränderungen, nämlich von Stase und Ödem und der Hämorrhagie gedeutet werden; aber auch diese Auffassung zeigt sich nicht hinreichend, denn wir finden nie derartige kolossale Plasmazellenanhäufungen bei anderweitigen Prozessen, wo die eben genannten Vorkommnisse sich auch abspielen, so beispielsweise bei den Angiomen, bei dem einfachen Ödem oder bei Blutextravasaten in der Haut. Nach reiflicher Überlegung scheint mir die Annahme der Wahrheit noch am nächsten zu kommen, daß diese entzündliche 
Proliferation von derselben unbekannten Ursache angeregt wird, die der ganzen Krankheit zu grunde liegt.

Nachdem wir im vorhergehenden die Histogenese der verschiedenen Komponenten des K.schen Sarkoms festgestellt haben, kommen wir nun auf die sukzessiven histologischen Vorgänge zu sprechen. Die Klinik lehrt, daß die kutanen Erscheinungen entweder als flache infiltrierte Flecken oder als Knötchen auftreten; sehr häufig findet sich auch ein kombinierter Typus, indem auf einem diffus infiltrierten Fleck im Laufe der Zeit Knötchen aufschießen. Dementsprechend können wir auch anatomisch zwei Grundtypen unterscheiden, $d$. h. die diffuse Infiltrierung der Kutis durch die Tumorzellen und die Bildung von abgegrenzten Herden. Diese Erscheinungen hängen offenbar in erster Linie von dem primären Sitz der Neubildung ab, indem die Herde, die sich in den oberflächlichen Schichten der Haut entwickeln, die Epidermis leicht emporwölben, während dies nicht gut geschehen kann, wenn es sich um die tieferen, zwischen den derben Bündeln des Corium reticulare gelegenen Herde handelt. Auch das mehr oder weniger schnelle Wachstum des Tumors kann möglicherweise in dieser Hinsicht von Bedeutung sein. Wir wissen ferner von der klinischen Beobachtung und zwar ist das am besten in den abgegrenzten Herden zu sehen - dal die Tumoren in der ersten Zeit ihres Auftretens weich und wegdrückbar sind und dann allmählich härter werden, sich verkleinern, ja unter Umständen sich vollkommen involvieren können. Das steht ebenfalls mit den Ergebnissen der anatomischen Untersuchung in bestem Einklang. Wie oben gesagt, bestehen die meisten Herde aus gemischten Veränderungen, d. h. es treffen Blutkapillar- und Spindelzellenneubildung zusammen. Kurz sei betont, daß, ohne einen histologischen Zusammenhang heranziehen zu wollen, sich dies in der Weise erklären läßt, daß eine gemeinsame Ursache, an Ort und Stelle wirkend, diese Veränderungen seitens des Gefäßsystems und des Bindegewebes gleichzeitig hervorruft. Die gegenseitigen Verhältnisse zwischen Blutgefäßen und zelliger Neubildung sind sehr wechselnd und allgemein geltende Regeln sind nicht zu geben. Im großen und ganzen kann man aber sagen, daß, mit der Zeit, die Blutkapillaren nach und nach abnehmen und da- 
gegen die Spindelzellen überwiegen, so daß letztere in älteren Herden den größten Teil der Neubildung ausmachen. Das Überwiegen der Spindelzellen bedingt das klinisch nachweisbare Härterwerden der Knoten.

Die Spindelzellen machen im Laufe der Zeit weitere Veränderungen durch. Die häufigste derselben ist die fibröse Umwandlung, worauf namentlich Philippson und Sellei hingewiesen haben. Die Spindelzellen erscheinen dann in einem dichtfaserigen Gewebe gleichmäßig eingebettet. Das Protoplasma sieht nicht mehr saftreich und feingranuliert aus, sondern ist sehr. spärlich, oft ist überhaupt keines zu sehen; der Kern ist ein stark sich färbendes Stäbchen geworden, das den Bindegewebskörperchen ähnlich aussieht. Wir erklären uns solche histologische Bilder auf dem einfachsten Wege, durch die Annahme eines Reiferwerdens des Gewebes. Es wiederholen sich hier Vorgänge, die wir bei dem Granulationsgewebe, sowie bei gewissen, durch die Erreichung höherer Entwicklungsstufen charakterisierten Neubildungen, so z. B. bei dem zellreichen Fibrom zu treffen gewohnt sind. Gleiches läßt sich an den Herden der inneren Organe, besonders deutlich an denjenigen des Lungenparenchyms feststellen (vgl, die histologische Beschreibung der Lungenpräparate).

Philipp s on beschrieb auch eine schleimige Degeneration der Knoten; die Neubildung soll dann aus großen, runden Zellen bestehen, deren Kern gut erhalten und färbbar ist, während im Protoplasma zahlreiche Vakuolen vorhanden sind. Sellei bestätigt diesen Befund. Ich habe in meinen Präparaten diese Art von regressiven Veränderungen nicht beobachten können.

Kaposi erklärte bekanntlich die Spontanheilung der Herde durch die zahlreichen Hämorrhagien und die Fibrininfiltration und -verschrumpfung; diese Auffassung hat auch später Anhänger gefunden. Philipp s on dagegen hält solche Vorgänge für belanglos in bezug auf das Zurückgehen der Herde. Ich muß im wesentlichen Philipps on beistimmen, denn es läbt sich gewöhnlich sowohl klinisch wie anatomisch kein Zusammenhang zwischen den Blutungen und den Involutionserscheinungen der Herde nachweisen; außerdem sind grö- 
Bere Fibrineinlagerungen recht selten $z u$ treffen. Nur in einzelnen, vorwiegend oder ausschließlich aus Blutkapillaren sich zusammensetzenden Herden könnte die Zerreißung der Gefäßwand und der Blutergub ins Gewebe insofern von Bedeutung sein, weil dadurch die Obliteration der erweiterten Kapillaren und eine entsprechende Verkleinerung der Geschwulst herbeigeführt wird. Ich habe manche Präparate gesehen, die eine solche Erklärung zuließen; allerdings ist diesem Vorgang nicht allzu große Bedeutung für das Zurückgehen der Herde beizumessen, auch deswegen, weil es stellenweise scheint, als ob gerade die Hämorrhagien den Anstoß zu der Spindelzellenwucherung geben.

Der Vollständigkeit halber sei schließlich noch erwähnt, daß im Tumorgewebe die elastischen Fasern vollkommen fehlen.

\section{Zusammenfassung.}

Aus den eigenen Beobachtungen und aus der Sichtung der einschlägigen Literatur hat sich folgendes ergeben: In bezug auf die geographische Ausbreitung des Sarcoma idiop. mult. haemorrh. läßt sich in Übereinstimmung mit den Angaben früherer Autoren feststellen, daß die Krankheit eine ausgesprochene Bevorzugung für bestimmte Länder aufweist, während andere Länder verschont bleiben. Die vielfach gemachte Behauptung, daß das Leiden vorzugsweise die semitische Rasse befällt, hat sich als nicht genügend begründet herausgestellt. Das Vorhandensein einer allgemeinen Disposition (Männer des Arbeiterstandes) steht sicher; überdies ist zuweilen, wie in einem selbstbeobachteten Falle, auch eine örtliche Disposition gewisser Körperteile zur Erkrankung nachzuweisen. Was die ersten Anfänge der Krankheit betrifft, so ist in einer ganzen Reihe von Fällen festgestellt worden, daß die Krankheit mit einem einzigen Herd begonnen hat; demnach bedarf die ursprüngliche Beschreibung $\mathrm{K}$ a pos is, der ein multiples, gleichzeitiges Auftreten der Krankheitsherde geschildert hatte, einer Modifizierung. Zuweilen hat sich der erste Herd des K.schen Sarkoms im Anschlub an ein Trauma entwickelt. 
Während des Krankheitsverlaufes eines schweren Falles von K.schen Sarkom ist es uns gelungen, die Beobachtungen $\mathrm{Ph}$ ilippsons bestätigend, die hämatogene Entstehung der Herde in der Haut festzustellen. Die Krankheitsdauer ist sehr verschieden; in 12 Fällen, die im letzten Dezennium in der hiesigen Klinik behandelt wurden, schwankte dieselbe zwischen 2 und 10 Jahren. Bei der Sektion zweier Fälle wurden Sarkomherde in den Lymphdrüsen, in dem Gastrointestinaltraktus, in der Leber und besonders zahlreich in den Lungen nachgewiesen. Von der Arsenmedikation sahen wir wenig Frfolg; auch die Arseneinführung mittelst Eleltrophorese (Winkler) hat sich nicht bewährt. Es wäre dagegen möglich, daß die Aussichten einer Heilung durch die frühzeitige Exzision des Primärherdes weit besser sich gestalten würden.

Histologisch haben wir bei dem K.schen Sarkom drei verschiedene Gewebsveränderungen: Eine Wucherung von Blutkapillaren, eine Wucherung von Lymphkapillaren und eine Neubildung von jungem, zelligem Bindegewebe, welch letzteres die normalen Entwicklungsstadien durchmacht und endlich fibrös entartet. Die in den Krankheitsherden sich befindenden, rein entzündlichen Zellformen (Lymphozyten und Plasmazellen) dürften wahrscheinlich, wenigstens zum großen Teil, mit der Natur des Prozesses selbst in direkter Beziehung stehen. Die Rückbildung der Herde ist zumeist auf eine fibröse Veränderung derselben zurückzuführen. Den Hämorrhagien kommt in dieser Hinsicht nur eine sehr beschränkte Bedeutnng zu.

\section{Bemerkungen zu dem vermutlichen Wesen des sog. Sarcoma idiop. mult. haemorrh.}

Bekanntlich hat Kaposi auf dem XI. medizin. intern. Kongresse betreffs der Auffassung des S. i. m. h. die Unmöglichkeit hervorgehoben, die pathologisch-histologische Stellung dieser Krankheit zu der Zeit mit Sicherheit zu bestimmen, und rorgeschlagen, dieselbe in einer besonderen Gruppe mit anderen in mancher Hinsicht analogen Krankheitsprozessen als s a r k o mähnliche oder sarkoide Geschwülste zusammenzu- 
fassen. Das Bestreben der Autoren, die sich nach Kaposi mit der Erforschung der Krankheit befaßt haben, war ständig darnach gerichtet, den Prozeß aus der provisorischen Gruppe der "Sarkoide" herauszunehmen und ihm eine gut definierte Stellung in der Pathologie zu schaffen. Dieses Ziel ist heutzutage noch nicht erreicht. Ohne die einzelnen Autoren aufzuzählen, beschränke ich mich auf den Hinweis, daß hauptsächlich zwei verschiedene Ansichten über die Natur des Leidens bestehen: Die Einen anerkennen in der K.schen Krankheit eine geschivulstmäßige Neubildung; Andere dagegen halten an der Trennung des Prozesses von den echten Tumoren fest und plaidieren für die Gehörigkeit zu den Infektionskrankbeiten. Stichhaltig wäre für die Ietztgenannten Autoren die ätiologische Forschung, d. h. der Befund des Erregers; das ist aber bisher weder durch die bakteriologische Untersuchung des erkrankten Gewebes noch durch die Tierexperimente geglückt. ${ }^{1}$ )

Um der Frage über das Wesen der Krankheit näher zu treten, sind wir nun auf klinische und anatomische Erwägungen angewiesen. Wenn man zunächst die Auffassung des Leidens als Sarkom berücksichtigt, so ist u. a. folgenden Tatsachen Rechnung zu tragen:

1. Wie oben auseinandergesetzt, hat das sog. K.sche Sarkom eine ausgeprägte Bevorzugung für bestimmte Länder. Auch die echten Geschwülste kommen freilich nicht in allen Ländern gleichmäßig, sondern in einigen Gegenden häufiger, in anderen wieder seltener vor; sie zeigen aber dies lange nicht in so hohem Grade, wie bei der in Rede stehenden Krankhcit. Will man die K.sche Dermatose als geschwulstmäßige Neubildung auffassen, so ist doch die erwähnte Eigentümlichkeit wenigstens als sehr merkwürdig zu bezeichnen.

1) Ich habe auch ziemlich zahlreiche Impfversuche mit Gewebsfragmenten und Blut meiner Patienten an Kaninchen und Meerschweinchen ausgeführt, ohne jedoch zu einem positiven Resultat zu gelangen. Einmal sah ich nach der Inokulation des durch das Ausquetschen eines Herdes von K.schem Sarkom gewonnenen Breies an der Kaninchenschnauze an derselben Stelle ein erbsengroßes, rötlicbes, derbes Knötchen sich bilden, das später in etwa einem Monat vollkommen resorbiert wurde. - Auch die Überimpfung von Sarkomstückchen auf gesunde Hautpartien bei demselben Kranken war erfolglos (vgl. Fall 2). 
2. Wir sehen, daß die Herde des Sarcoma idiop. nach kürzerem oder längerem Bestehen der Krankheit mehr oder weniger zahlreich sind, an den Akra (Hände, Füße, Kopf, Genitalien) lokalisiert sich finden und sich meist symmetrisch verteilen. Wenn man dieses Verhalten durch die Geschwulstlehre erklären wollte, so wäre in erster Linie die Frage zu entscheiden, ob primäre oder sekundäre Multiplizität der Geschwulstbildung vorliegt. Die Annahme einer sekundären Multiplizität, d. h, einer Verbreitung der Geschwulst von einem Primärherde aus, ist wenig wahrscheinlich, denn eine solche Art von Metastasenbildung, wie dies bei dem Sarcoma idiop. der Fall wäre, ist bei den echten Sarkomen unbekannt, ja sie widerspricht den Gesetzen, die die Lokalisation der Tochtergeschwülste bei den echten Sarkomen bestimmen. Man sollte also am besten mit der Annahme einer primär multiplen Geschwulstbildung sich zufrieden stellen (was schon Kaposi angenommen hatte), wobei, angesichts der Symmetrie der Hautreränderungen, auch die Möglichkeit der Mitwirkung nervöser Einflüsse nicht ausgeschlossen werden könnte (Kreibich).

3. Was den gesamten Verlauf der K.schen Dcrmatose betrifft, so ist wohl der Ausgang derselben im großen und ganzen ein schlechter. Hervorzuheben ist immerhin die im Vergleich zu den echten Sarkomen ungewöhnlich lange Dauer der Krankheit, beim besten Wohlbefinden des Patienten, trotz der ausgedehnten kutanen Veränderungen. Die einzelnen Herde zeigen im allgemeinen keine nennenswerte Bösartigkeit: es tritt kein ulzeröser Zerfall ein, das Wachstum ist ein begrenztes, Involutionserscheinungen kommen sehr häufig vor. Obige Tatsachen sind vielfach gegen den Sarkomcharakter der Neubildung verwertet worden, weil die echten Sarkome bekanntlich sich anders verhalten. Demgegenüber bat Fan o, der für die Zugehörigkeit des Leidens zu den Sarkomen eingetreten ist, diese Erscheinungen in der Weise erklären wollen, daß sie nicht als wesentliche Eigenschaften der Krankheit, sondern als akzidentelle, durch die besonderen Verbältnisse des Muttergewebes, d. h. der Haut bedingte Eigentümlichkeiten aufzufassen seien: demnach sollten sie an der Sarkomnatur der Krankheit nichts ändern. 
4. Anatomisch finden wir bei dem K.schen Sarkom als allgemeine Charaktere folgendes: Die Neubildung wächst hauptsächlich peripherisch und infiltriert diffus das Grundgewebe; nur selten finden sich Tumoren, die expansiv wachsen und das Nachbargewebe verdrängen. Daher kommt es, daß die Grenzen zwischen gesundem und krankhaftem Gewebe des öfteren unscharf erscheinen. Diese Befunde sind wiederum von vielen Autoren gegen den echten Sarkomcharakter angeführt worden; freilich muß man zugeben, daß sie nicht als ganz sichere Unterscheidungsmerkmale gelten können, da auch echte Sarkome unter Umständen die obigen Charaktere darbieten können. Zieht man die feineren, histologischen Verhältnisse in Betracht, so begegnet die Einreihung des Prozesses einer bestimmten Gruppe der Geschwulstklassifikation gewissen Schwierigkeiten. Wir finden nämlich Tumoren, die den Bau von Kapillarhämangiomen oder Lymphangiomen zeigen, während andere Herde das Aussehen eines spindelzelligen Sarkoms (er. Fibrosarkoms) haben.

5. Betrachtet man die Befunde der inneren Organe, so erfordern diejenigen an den Lungen das meiste Interesse. Der Reichtum der Lungen an metastischen Herden, wie ich in meinen Fällen 3 und 4 nachgewiesen habe, steht allerdings in guter Übereinstimmung mit den allgemeinen Eigenschaften der metastatischen Sarkome. Es bleibt aber immerhin auffallend, daß sich in den Lungen trotz sorgfältiger Untersuchung nichts finden ließ, was auf die Entstehung der Töchtergeschwülste von embolisch verschleppten Tumorzellen hindentete; man hatte dagegen entschieden den Eindruck, daß die Knötchen aus der Wucherung der an Ort und Stelle vorhandenen Elemente hervorgingen, welcher Eindruck dadurch verstärkt wurde, daß die Tumorherde in den Lungen nicht scharf abgesetzte Einlagerungen mit Verdrängung des umgebenden Lungenparenchyms bildeten, sondern, gleichwie in der Haut, das Nachbargewebe diffus infiltrierten.

Vom Gesichtspunkte der In fe ktion s th e or ie aus, kommt etwa folgendes in Betracht:

a) Die geographisch unregelmäßige Verteilung der K.schen Dermatose ist mit der Auffassung des Leidens als Infektionskrankheit sehr gut in Einklang zu bringen. 
b) Durch die Annahme eines Infektionswesens könnte der Gang der Krankheit, nach Philippson, auf die folgende Weise rekonstruiert werden: Das Virus dringt von außen in die Haut (durch Traumen? s. o.) und bedingt an der Eintrittspforte die Entstehung des ersten Krankheitsherdes. Nachdem es hier längere o. kürzere Zeit lokalisiert geblieben ist (Aussicht der Heilung durch Exzision!), dringt es in die Blutbahn und gelangt von neuem in die Haut und zwar zunächst in die Hand- und Fußregionen. Diese Art der Ausbreitung entspricht in der Tat den Gesetzen der infektiösen, hämatogenen Metastasen in der Haut.

Die Infektionstheorie vermag also die Lokalisation und die Symmetrie der Hautveränderungen ungezwungen zu erklären.

c) Auf diese Weise werden die äußerst chronische Dauer der Krankheit und das Ungestörtbleiben des Allgemeinzustandes bei diesen Sarkomkranken ganz verständlich. Aber auch manche Eigentümlichkeiten der Hauterscheinungen können durch die Infektionstheorie eine hinreichende Erklärung finden. Setzt man eine Kurzlebigkeit und Hinfälligkeit des vermutlichen infektiösen Agens voraus (was doch nicht ohne Analogien wäre, vgl. Tuberkulose u. Syphilis), so versteht man, warum die Tumoren nicht ins Schrankenlose wachsen, sondern auf einer gewissen Höhe der Entwicklung stationär bleiben und sich zurückbilden können.

d) Es fragt sich nun ob der histologische Befund mit der Auffassung einer chronisch entzündlichen Gewebsneubildung vereinbar sei. In dem sog. K.schen Sarkom finden wir bei Anwesenheit von rein entzündlichen Zellformen (Lymphozyten, Plasmazellen) eine Wucherung von gefäßreichem, zelligem Bindegewebe, das im Laufe der Zeit höhere Organisationsstufen erreicht. Viele Autoren (Sellei, Kreibich u. a.) deuten die bei diesem Prozeß wuchernden Spindelzellen nicht als Sarkomzellen sondern als gewöhnliche Fibroblasten eines Granulationsgewebes. Dieser Auffassung steht $\mathrm{m}$. E. prinzipiell nichts im Wege. Aus der Granulomnatur des Leidens kann die infektiöse Ursache desselben abgeleitet werden.

e) In unseren Fällen 3 und 5, wo die Krankheit schon weit fortgeschritten war, bestand im Gegensatz zu den übrigen, 
leichteren Fällen eine Affektion der regionalen Lymphdrüsen, es ging also eine Ausbreitung der Krankheit in zentripetaler Richtung auf dem Lymphwege vor sich. Bei der Sektion der betreffenden Fälle wurde die Beteiligung des Lymphsystems an der Verbreitung der Krankbeit in den inneren Organen be stätigt; wir fanden nämlich, in beiden Fällen übereiustimmend, die peribronchiale Lagerung der Tumorknötchen in den Lungen. Es möge, betreff der Befunde aus den Lungen auf die Ähnlichkeit mit den bei Infektionskrankheiten sich abspielenden Vorgängen ( $\mathrm{vgl}$. Lymphangitis peribronchialis tuberculosa) hingewiesen werden.

Bei der Entscheidung des Wesens des K.schen Sarkoms müssen wir die angeführten Momente erwägen. Es ergibt sich aus denselben, daß der Annahme der Geschwulstnatur des Leidens Manches im Wege steht; wenn man auch einige Vorkommnisse durch eine ganz besondere Ausnahmestellung des Prozesses erklären kann, so sind andere Eigentümlichkeiten der Krankheit mit der Geschwulstlehre kaum vereinbar.

Zweifellos verlockender erscheint die Infektionstheorie. Diese hätte sicher noch mehr Anhänger gefunden, als deren sie sich heute freut, wenn die eigentümliche anatomische Struktur der Krankheitsherde gewissermaßen nicht befremdend gewirkt hätte. Denn wir müssen offen sagen: der histologische Bau der Kaposischen Krankheit ähnelt demjenigen der Sarkome. Bis heute kennen wir keine Neubildung, deren infektiöse Natur sichergestellt ist, die derartige histologische Bilder aufweist, wie das K.'sche Sarkom darbietet. Unsere geläufigen infektiösen Granulome sehen histologisch wohl anders aus.

Daß die Annahme eines infektiösen Agens bei dieser Krankheit immerhin bestechend gewesen sei, ersehen wir daraus, daß auch manche Autoren (z. B. Bernhardt), die an der Sarkomnatur festhalten, keinen Anstand genommen haben, in diesem speziellen Fall die sarkomatöse Wucherung auf die Wirkung eines Virus zurückzuführen. Demgemäß hätten wir nach diesen Autoren, falls der Erreger des K.schen Sarkoms entdeckt würde, ein schönes Beispiel, daß sarkomatöse Geschwülste von infektiösen Ursachen erzeugt werden können und 
zugleich eine Stütze für die viel erörterte parasitäre Theorie der Sarkome.

Wie oben angeführt, bildet aber nicht der histologische Befund einen zwingenden Grund, um die geschwulstmäßige Natur des Leidens anzuerkennen, ja die Anatomie der Erkrankung ist prinzipiell auch mit der Granulomnatur vereinbar. Es erscheint demnach sehr fraglich, ob und inwiefern die in bezug auf das sog. Kaposi sche Sarkom gezogenen Schlüsse auf die "echten" Sarkome übertragbar sind.

Meinem nun verewigten unvergeßlichen Lehrer Prof. M i b elli fühle ich mich für die Überlassung des Materials und das stete Interesse, das er dieser Arbeit entgegengebracht hat, zu großem Danke rerpflichtet. Auch dem jetzigen Vorstande der Klinik, Herrn Prof. Pelagatti, erlaube ich mir bei dieser Gelegenheit für seine freundliche Unterstützung meinen Dank auszusprechen.

\section{Literatur.}

Diegesamte Zahl der Fälle von Sarcoma idiop. mult. haemorrh., die von den hierangeführten Autoren publiziert worden sind, beläuft sich a uf etwa 260 .

1. Azua. Sarcomatosis cutanea idiopatica multiple pigmentaria hemorragica, tipo Kaposi. Actas dermo-sifiliográficas. Diciembre 1909. Enero 1910. Nr. 2.

2. Babes und Ka lind e ro. Ein Fall von idiopatbischem multiplem Pigmentsarkom der Haut mit Beginn an den Extremitäten. Ann. aus dem Inst. f. Path. u. Bakt. in Bukarest. Ref. Monatsh. f. prakt. Derm. Bd. XIV. p. 283. 1892.

3. Bayet. Fall von Sarkomatosis idiopathica. Bull. de la Soc. belge de derm. et de syph. 1906-1907. Ref. Monatsh. f. prakt. Derm. Bd. XLVII. p. 365.1908.

4. Balzer et Poisot. Lupus avec lymphangiectasies et lymphorhagies. Soc. franc. de derm. et de syph. Juli. 1906.

5. Berk. A case of multiple idiopathic haemorrhagic Sarcoma (Kaposi). Proceedings of the 6th intern. derm. Congress. New-York. Vol. 1. p. 159. 1908.

6. Bernhardt. Sarcomata idiopathica multiplicia pigmentosa cutis. Archiv f. Derm. u. Syph. Bd. XLIX. p, 207. 1899.

7. - Weitere Mitteilungen über Sarcoma idiopathicum multiplex pigmentosum cutis. Arch. f. Derm. u. Syph. Bd. LXII. p. 237. 1902.

8. - Sarcoma idiopathicum multiplex en plaques pigmentosum et lymphangiectodes. Eine eigentümliche Form der sog. Sarcomatosis cutis. Arch. f. Derm. u. Syph. Bd. XLIII. p. 239. 1902.

9. Ca mpa n a. Über Sarkomatose der Haut. XIr. Kongreß der ital. Ärzte zu Pavia. Sept. 1897. Sektion f. Syph. u. Hautkrankh. Ref. Monatsh. f. prakt. Derm. Bd. VII. p. 28. 1898. 
10. - Un altro caso di sarcoma idiopatico della cute accompagna to da evidenti sintomi di trofismo. Clinica dermosif. d. Universita di Roma. fasc. 1. 1897.

11. - Un altro caso di sarcoma idiop. della cute, accompagnato da alterazioni anatomiche del sistema nervoso. Clinica Dermosif. d. Univ. di Roma 1900. Fasc. 1.

12. Carruccio. Un caso di cosidetto sarcoma primitivo idiop. teleangiect. della cute. Boll. della R. Accad. med. di Roma. 1899.

13. Chirivino. Saggio di Roentgenterapia nella sarcomatos. cutanea. Giorn. internaz. d. scienze mediche. Anno XXVIII. p. 312. 1906. 14. D'A nt on a. Sulla sarcomatosi cutanea multipla. Gazz. d. Osped. e di Clin. 1897.

15. D e A m i cis. Dermopolimelano sarcoma idiopatico. Napoli. 1882. 16. - Sulla sarcomatosi cutanea idiopatica. Gazz. d. Osped. e d. Clin. Nr. 64. 1897.

17. - Über die Hautsarkomatose. Monatsh. f. prakt. Dermat. Bd. XXV. 1897.

18. De Luca. Su di un caso di angiosarcoma multiplo idiopatico degli arti inferiori. Lezione clinica. Catania. 1895.

19. Ehrmann. Demonstration eines Falles von S. i. m. h. Wiener derm. Gesellschaft. 18. Januar 1911. Ref. Archiv f. Dermatol. u. Syphilis. Bd. CVII. p. 444. 1911.

20. Fasal. Demonstration eines Falles von S. i. m. h. Wiener derm. Gesellschaft. Sitz. 25. Nov. 1908. Ref.

21. Fileti. Contributs alla casistica della sarcomatosi cutanea primitiva. Giorn. it. d. mal. veneree e d. pelle. 1895.

22. Fokin. Demonstration eines Falles von S. i. m. h. - Vener.derm. Gesellschaft zu Moskau. Mai. u. Dez. 1897. Ref. Monatsh. f. prakt. Derm. Bd. XXV. p. 83.1997 und Bd. XXVI. p. 102. 1898.

23. Fordice. Multiple pigmented sarcoma of the skin (Kaposi). Journ. of cut. and gen.-urin. diseases. 1895 .

24. Funk. Klinische Studien über Sarkome der Haut. Monatsh. f. prakt. Dermat. Bd. I. p. 19. 1889.

25. Geza Dieballa. Über einen mit Lymphozytose einhergehenden Fall von Sarcoma multiplex cutis. Wiener klin. Wochenschrift. Nr. 22. 1907.

26. Gottheil. Sarcoma cutis of the idiopathic multiple haemorrhagic (Kaposi) and ordinary types combined. Manhattan derm. Society. 1909. Ref. The Journ. of cut. diseases. Vol. XXVIII. p. 103. 1910.

27. Gravagna. Sulla sarcomatosi cutanea idiopatica. Giorn. ital. d. mal. veneree e d. pelle. 1897. Fasc. If. p. 764 .

28. Halle. Ein Beitrag zur Kenntnis des Sarcoma idiop. mult. haemorrh. (Kaposi). Arch. f. Derm. u. Syph. Bd. IXXXII. 1904.

29. Hallopeau et Jeanselme. Sur une sarcomatose cutanée offrant les charactéres cliniques d'une lymphangite infectieuse. 2. intern. derm. Kongreß. Wien. 1892. p. 665. ${ }^{1}$ )

1) $\mathrm{Ob}$ der von $\mathrm{H}$. und J. unter dieser Bezeichnung beschriebene Fall als Kaposisches Pigmentsarkom aufzufassen ist, wie manche Autoren anzunehmen scheinen (z. B. Spiegler in M račeks Handbuch) möchte ich doch bezweifeln. Die klinische Schilderung, die H. und J. von ibrem Falle geben (Beschränkung der Affektion auf die l. obere Extremität, Auftreten subkutaner Knoten den Lymphbahnen entlang, große Neigung der Herde zur Ulzeration und Fistelbildung usw.) weicht vom Bilde des $K a p o s i s c h e n$ Sarkoms bedeutend ab. Auch der histologische Befund gleicht nicht demjenigen des S. i. 
30. Halkin. Ein Fall von teleangiektatischem bämorrh. Sarkom. Bull. de la Soc. belge de Derm. et de Syph. Februar 1908. Ref. Monats. f. prakt. Dermat. Bd. XLVII. p. 569. 1908.

31. Hard a w a y. Journ. of cut. and ven. diseases. Jan. 1883 und Okt. 1884. Zit. von Perrin.

32. Hartzell. A case of idiopathic multiple hemorragic sarcoma (Kaposi). Proceedings of the, 6 th intern. med. Congress. New-York. p. 176-341. 1908.

33. Hava 8. Ein Fall von Sarcoma idiop. mult. pigmentodes cutis, Ungarische derm.-urol. Gesellschaft zu Budapest. 27. April 1899. Ref. Monatsh. f. prakt. Derm. Bd. XXIX. p. 118. 1899.

34. Hiorth. El Tilsolde of idiopatik multipell Pigmentsarkom (Kaposi). Klinik Aarbog, Christiania. 1886. Ref. Vierteljahressehrift fo Derm. u. Syph.

35. Hintz, Demonstration eines Falles von S. i. h. Wiener derm. Ges. 20. April 1910. Ref. Archiv f. Derm. u. Syph. Bd. CIII. p. 368. 1910.

36. Hitrowo. Zur Histogenese des Sarcoma cutis mult. haamorrh. (Kaposi). Russki Wratch. Nr. 26. 1908. Ref. Derm. Zeitschrift. Bd. XV. p. 78. 1908.

37. Hutchinson. Archives of Surgery. Vol, V. p. 237 u. Vol.

VI. p. 132.

38. - Smaller Atlas of Clinical Surgery. Plate 61.

39. Jakson. Report of a case of multiple idiopathic pigmented sarcoma (Kaposi type). Report of transactions in the dermat. Section Montreal. Aug.-Sept. 1897. Ref. Journal of cut. and gen.-urin. diseases. Vol. XV. 1897.

40. Jordan. Demonstration eines Falles von S. i. m. h. Venereol. derm. Gesellschaft. Moskau. 5. Febr. 1901. Ref. Monatsh. f. prakt. Derm. Bd. XXXII. p. 345, 1901 und Bd. XLI. p. 200, 1905.

41. Justu s, Über Übertragung von S. i. m. h. (Kaposi) auf Tiere. Verhandl. des XVI. med. intern. Kongreßes zu Budapest. 1909.

42. K a posi. Idiopathisches multiples Pigmentsarkom. Arch. f. Derm. u. Syph. IV. Jahrgang. p. 265. 1872. p. 268 .

43. (Hebra-) Kaposi. Handbuch der Hautkrankheiten. Bd. II.

44. - Demonstration eines Falles von S. i. m. h. - K. k. Gesellschaft d. Ärzte in Wien. Okt. 1885. Ref.: Monatsh. f. prakt. Derm. Bd. V. p. 38. 1886.

45. - Demonstration eines Falles von S. i. m. h. Wiener derm. Gesellschaft. 20. Okt. 1890.

46. - Demonstration von 2 Fällen von $\mathrm{S}$. i. m. h. Wiener derm. Gesellschaft. März 1892. Ref. Monatsh. f. prakt. Derm. Bd. XV. p. 411. 1892 .

47. - Interpretazione da dare al sarcoma primitivo idiop. pigment, della cute e sua nomenclatura. Atti del XI. Congr. med. intern. Roma. p. 125. 1894. S. Diskussion: Majocchi, De Amicis, Pelizzari. Reale.

48. Ka sansky. Ein Fall von idiop. mult. Pigmentsarkom der Haut. Wratsch 1895. Nr. 16-17. Ref. Archiv f. Dermat. u. Syph. Bd. XXXIII. p. 238.1895 .

49. Kempff. Demonstration eines Falles von S. i. m. h. Verhandl. der derm. Gesellschaft zu Stockholm. 2. Juni 1910. Ref. Arch. Bd. CIV. p. 116.1910.

50. Köbner. Heilung eines Falles von allgemeiner Sarkomatose der Haut durch subkutane Arseneinspritzungen. Berl. klin. Wochenschrift. 1883.

51. - Ein Fall von idiopathischem multiplem Pigmentsarkom der Extremitäten. Berl. klin. Wochenschrift. Nr. 2. 1886. 
52. - Demonstration eines Falles von S. i. m. h. - Verhandl. d. derm. Sektion beim X. intern. med. KongreB zu Berlin. Ref. Arch. f. Derm. u. Syph. Bd. XXIII. p. 119. 1891.

53. Kohler. Sarcome cutanée idiopathique multiple. Journ. of cut. diseases. p. 5. 1902. Ref.: Journ. mal. cut. et syph. Tome XIV. p. 293. 1902. 54. Kracht. Demonstration eines Falles von S. i. m. h. - Ven.derm. Gesellschaft zu Moskau. April 1898 und April 1899. Ref. Monatsh. f. prakt. Derm. Bd. XXVI. p. 501. 1898 und Bd. XXIX. p. 174. 1899. 55. Kreibich. Über Granulome. Arch. f. Derm. u. Syph. Bd. XCIV. 1908.

56. Kren. Demonstration eines Falles von S. i. m. h. Wiener derm. Gesellschaf p. 374.1910.

57. Kudisch Sarcoma cutis idiop. pigment. Kaposi. Russ, Journ. f. Haut u. ven. Krankh. 1902. Ref.

58. L e de rmann. Vorstellung eines Falles von S. i. m. h. Berl. dermat. Gesellschaft. 2. Februar 1904. S. Diskussion: Wech selman n, Holländer. Ref. Derm. zeitschrift. Bd. XI. p. 429. 1904.

59. - Wiederholte Vorstellung eines Falles von S. i. m. H. Berl. derm. Ges. 9. Juli 1907. Ref. Derm. Zeitscbr. Bd. XIII. p. 658. 1907. 60. Lesser. Vorstellung eines Falles von S. i. m. h. Berl. derm. Gesellschaft. Juni 1907. Ref. Derm. Zeitschrift. Bd. XIV. p. 568. 1907. 61. - Sarcoma haemorrh. mult. Gesellschaft d. Charité-Ärzte. 29. Nov. 1908. Monatsh. f. prakt. Derm. 15. März 1909. p. 263.

62. Li e berthai. Sarcomatosis cutis. Amer. med. Assoc. Journal.

Nr. 23. 1902. Ref. Monatsh. f. prakt. Derm. Bd. XXXVII. p. 407. 1903. 63. - A case of multiple haemorrh. sarcoma (Kaposi). Chicago dermat. Society. 23. Oct. 1908. Journ. of cut. diseases juin. 1909. p. 256. 64. - Idiopathisches mult. haem. Sarkom (Kaposi). Trauma, ein ätiologisches Faktor. The Journ. of cut. Diseases nov. 1909.

65. Lukasievicz. Sarcoma idiop. cutis mult. - Societé méd. de Lemberg. 29. Oct. 1909.

66. L urj6. Ein Fall von S. i. m. h. Russische Zeitschrift f. Derm. u. vener. Krankh. Nr. 11. 1902. Ref. Monatsh. f. prakt. Derm. Bd. XXXVI. p. 394. 1903.

67. Lu stgarten. Demonstration eines Falles von S. i. m. h. New Yorker derm. Gesellschaft. Nov. 1907. Ref. Monatsh. f. prakt. Derm. Bd. XXVI. p. 553. 1898.

68. Ma ckenzi e. Brit. Journ. of Dermat. June 1890.

69. M a c L e od. Notes on the histopathology of multiple idiopathic

haemorragic sarcoma. Brit. Journ. of Derm. Vol. XVII. pag. 173. 1905.

70. $\mathrm{Mag}$ a lia no. Di alcune trapiantazioni di tessuti del cosidetto sarcoma primitivo idiopatico della cute su eruzione sarcomatosa della cute medesima. Il Morgagni, anno $36^{\circ} .1894$.

71. Mai ec. Demonstration eines Falles von S. i. m. h. VIII. Kongreb d. deutschen derm. Gesellschaft in Sarajewo. Sept. 1903. Ref. Monatsh. f. prakt. Derm. Bd. XXXVII. p. 389. 1903.

72. Mariani. Sarkomatosis Kaposi mit besonderer Berücksich. tigung der viszeralen Lokalisationen. Arch. f. Derm. u. Syph. Bd. IIC. 1909 .

73. Martin. Sarcoma idiop. mult. haemorrbagicum. Rev. iberoameric. de ciencias medicas. Febr. 1907. Ref. Monatsh. f. prakt. Derm. Bd. XIJV. p. 3661907.

74. Massei. Le complicazioni laringee della sarcomatosi cutanea. Arch. ital. di laringologia. fasc. 4. p. 145 . 1899.

75. Mendes da Costa. Ein Fall von Kaposis Pigmentsarkom. Festschrift f. Unna. Bd. II. p. 212. 
76. Metscherski. Demonstration eines Falles von S. i. m. h. Vener.-derm. Gesellschaft zu Moskau. Febr. 1900. - Ref. Monatsh. f. prakt. Derm. Bd. XXX. p. 516. 1900.

77. Moberg. Demonstration eines Falles von S, i. m. h. - Verhandl, d. derm. Gesellschaft zu Stockholm. 28. Okt. 1909. Ref. Arch. f. Derm. u. Syph. Bd. CIV. p. 403. 1910.

78. Neisser. Demonstration eines Falles von S. i. m. h. Schle. sische Gesellschaft f. vaterländ. Kultur in Breslau. Febr. 1894. Ref. Monatsh. f. prakt. Derm. Bd. XIX. p. 545. 1894.

79. N e u mann. Demonstration eines Falles von S. id. m. haemorrh. Wiener derm. Gesellschatt. 20. April 1904. Ref. Archiv f. Derm. u. Syph. Bd. LXXII. p. 268. 1904.

80. Pelag atti. La sarcomatosi cutanea. Parma. 1902.

81. - Sul sarcoma molteplice primitivo del Kaposi. Giorn. ital. d. malattie ven. e della pelle. fasc. V. 1905.

82. Perrin. De la sarcomatose cutanée. Paris. 1886.

83. Piccardi. Metastatisches Angioma senile und seine Beziehungen zum sogenannten Sarcoma Kaposi. Monatsh. f. prakt. Dermat. Bd. LI. p. 241. 1910.

84. Pick W. Zur Kenntnis des Kaposischen Pigmentsarkoms. Arch. f. Derm. u. Syph. Bd. LXXXVII. 1907.

85. Pin i. Sarkoide der Haut. Bibliotheca medica. D. II. Heft 11.

86. Pyw owa roff. Demonstration eines Falles von S. i. m. h. Derm. u. venereol. Gesellschaft zu Charkow. März 1903. Ref. Derm. Zeitschrift. Bd. XI. p. 265.1904.

87. Philippson. Un caso di sarcomatosi della pelle conginuto a carcinomatosi viscerale. Rif. med. Nr. 165. 1898.

88. - Über das Sarcoma idiopathicum cutis Kaposi. Ein Beitrag zur Sarkomlehre. Virchows Archiv. Bd. CLVII. p. 58. 1902.

89. Pringle. Zwei Fälle von S. i. m. h. C. R. Congres intern. de dermat. et de syph. Paris. 1890.

90. Prota. Sarcoma multiplo idiop. emorragico dell' istmo delle fanci e della cute. Arch. ital. di laringologia. Aprile 1905.

91. Radaeli. Contributo alla conoscenza del sarcoma mult. idiop. emorr. della cute. V. Riunione della societa italiana di derm. e di sifil. Roma. 1901.

92. - Contributo alla conoscenza del sarcoma idiopatico multiplo emorragico della cute. Lo sperimentale. Fasc. VI. 1904.

93. - Nuove osservazioni sulla istologia patologica e sulla cura del sarcoma idiopatico multiplo della cute. Lo sperimentale. Fasc. III. 1906. 94. - Nuovo contributo alla conoscenza dell' angioendotelioma cutaneo (Sarc. idiop. multiplo) di Kaposi. X. Riunione della soc. italiana di derm. e di sifil. Roma. Dic. 1908.

95. R e a le. Tentativi d'inoculazione sperimentale del sarcoma cutaneo, tipo Kaposi, con speciale riguardo alla etiologia dei tumori. Napoli. 1902. 96. - Nuovi tentativi d'inoculazione sperimentali del sarcoma cutaneo, tipo Kaposi. Napoli. 1904.

97. Reitmann. Vorstellung eines Falles von S. i. m. h. nach der Roentgenbehandlung. Wiener derm. Gesellschaft. 15. Januar 1908. Ref. Monatsh. f. prakt. Derm. Bd. XLVII. p. 516. 1908.

98. - Vorstellung eines Falles von S. i. m. h. Wiener derm. Gesellschaft. 12. Februar 1908. Ref. Monatsh. f. prakt. Derm. Bd. XLVII. p. 562.1908.

99. - Vorstellung eines Falles von S. i. m. h. Wiener derm. Gesellschaft. 4. Nov, 1908. Ref.

100. Riehl. Vorstellung eines Falles von Sarcoma id. m. haemorrh. Wiener derm. Gesellschaft. 27. Mai 1903. Ref. Archiv f. Derm. u. Syph. Bd. LXVII. p. 296. 1903, 
101. - Vorstellung von 2 Fällen von S. i. h. Wiener derm. Gesellschaft. 27. Januar 1904. S. Diskussion: Ne u man n, Sa ch s. Ref. Archiv f. Derm. u. Syph. Bd. LXX. p. 134. 1904.

102. - Vorstellung eines Falles von id. m. Pigmentsarkom (Kaposi). Wiener derm. Gesellschaft. 20. April 1904. Ref. Arch. f. Derm. u. Syph. Bd. LXXII. p, 269. 1904.

103. Ris s o m. Vorstellung eines Falles von S. i. m. h. Berl. derm. Gesellschaft. 8. Dez. 1908. Ref.

104. Rona. Ein Fall von multiplem idiopathischem Sarcoma cutis (K a pos i). Ungarische derm.-urol. Gesellschaft in Budapest. 29. März 1899. Ref. Monatsh. f. prakt. Derm. Bd. XXIX. p. 117. 1899.

105. Sabella. Primi tentativi (comparativi) di inoculazione del sarcoma primitivo della cute. Fasc. III. p. 80. Nov. 1908.

106. Saveljew. Acrocangioma haemorrh. Kaposi bei einem 67jähr. Manne. Moskauer vener.-dermat. Gesellschaft. März 1909.

107. Sc haumann. Demonstration eines Falles von Sarc. i. m. h. Dermat. Gesellschaft zu Stockholm. 26. Januar 1911. Ref. Arch. f. Derm. u. Syph. Bd. CVII. p. 470. 1911.

108. Schlesing er. Vorstellung eines Falles von S. i. m. h. Berl. med. Gesellschaft. 24. Okt. 1906. Ref. Berl. klin. Wochenschr. Nr. 45. 1906.

109. Sc holtz. Multiples idiopathisches Hautsarkom (Kaposi). Verhandlungen der Breslauer derm. Vereinigung. Ref. Arch. f. Derm. u. Syph. Bd. LI. p. 311. 1900.

110. Scholtz u. Doebel. Bericht über das Arbeitsjahr 1906/1907. Scholtz: mult. idiop. haemorrh. Hautsarkom. Arch. f. Derm. u. Syph. Bd. XCII. p. 367. 1908.

111. S ch w im mer. Sarcoma pigmentosum diffusum multiplex. Intern. Atlas seltener Hautkrankh. H, 2. Tafel IV. Hamburg. 1890.

112. - Sarcomatose cutanée generalisée pigmentaire. C. R. Congrés intern. de derm. et de syph. Paris. 1890.

113. - Über das Pigmentsarkom und einige verwandte Affektionen. III. Congress of Derm. London. 1896.

114. Sedziak. Seltener Fall von Sarcomata multiplicia cutis et lympho-sarcoma tonsillae dextrae. Gazeta Lekarska. Nr. 44. 1892. (Zit. nach $\mathrm{Halle}$.)

115. Selborst und Polland. Ein Fall von S. i. m. h. (Kaposi). Areh. f. Dermatol. u. Syph. Bd. LXXXII. p. 33. 1906.

116. Sellei. Über das idiop. Ka p o s ische Sarcoma mult. haemorrh. Monatsh. f. prakt. Derm. Bd. XXXI. p. 413. 1900.

117. - Beiträge zur Pathologie des Kaposischen Granuloms. Monatsh. f. prakt. Derm. Bd. XXXIV. p. 497. 1902.

118. - Weitere Beiträge zur Pathologie des sog. Sarcoma mult. pigm. haemorrh, idiop. (Kaposi). Archiv für Derm. u. Syph. Bd. LXVI. p. 41.1903.

119. Semenow. Zehn Fälle von Sarcoma idiop, mult. cutis. Vortrag gehalten auf dem XII. intern. med. Kongreß zu Moskau. Monatsh. f. prakt. Derm. Bd. XXV. p. 539. 1897.

120. Sequeira. Case of idiopathic multiple Pigmentiarkoma. Brit. Journal of Derm. Vol. XIII. p. 201. 1901.

121. - Case of multiple idiop. pigment Sarcoma (Kaposi). Procee-

dings of the Royal Soc. of Medicine of London Dermat. Section. 20. Oct. 1908. p. 15. Ref. Brit. Journ. of Dermat. Nov. 1908. p. 376.

122. - Case of mult. idiop. pigmentary Sarcoma. Royal Soc. of

Medicine of London. Dermat. Section. Ref. Brit. Journ. of Dermat. November 1910 . p. 356 .

123. S herwell. Journ. of eut. and gen.-urin. diseases. 1897.

124. So m mer. Fall von S. i. m. h. Rev. de la Sociedad med

Argentina. Bd. IX. p. 669. Ref, Monatsh. für pr. Derm. Bd, XL. p. 159. 1905. 
125. Spiegler. Über die sogenannte Sarcomatosis cutis. Archiv f. Derm. u. Syph. Bd. XXVII. p. 163. 1894.

126. - Vorstellung eines Falles von S. i. m. h. Wiener dermatol.

Gesellsch. Mai. 1907. Ref. Monatsh. f. pr. Derm. Bd. XLV. p. 303. 1907. 127. Stanziale. Klinischer Bericht über 410 dermo-syphilidol. Krankheitsfälle. Gazz. d. Ospedali. 1890.

128. S to uk ovenk off. Sarcomes multiples pigm. idiopathiques de la peau. V. Congr. de méd. russes 1904. Section de Dermat. Ref. Journ. de mal. cut. et syph. Vol. VI. p. 678. 1894.

129. Stravino. Sarcomatosi cutanea primitiva emorragica con speciale riguardo alla etiologic. Giorn. it. d. mal. ven. e d. p. 1898. Fasc. II. 130. T a n t u r ri. Del sarcoma idiopatico parvicellulare telangettasico pigmentato della pelle. Il Morgagni. 1877. p. 493.

131. T i n z ew. Sarcoma idiop. pigm. (haemorrh.) mult. cutis (Kaposi). Gesellschaft f. wiss. Med. u. Hyg. zu Charkow. Okt. 1896. Ref. Monatsh. f. prakt. Derm. Bd. XXXIV. p. 312. 1897.

132. Tomas chewitse h. Demonstration eines Falles von S. i. m. b. Moskauer ven.-derm. Gesellschaft. Februar 1906. Ref. Monatsh. f. prakt. Derm. Bd. XLII. p. 413. 1906.

133. Tom masoli. Sarcomatosi cutanea. Acc. med.-chir. di Palermo.

23 Genno 1898. Ref. Giorn. ital. d. mal. veneree e d. pelle. p. 404. 1898. 134. Tör rök. Zwei Fälle von Sarcoma idiop. mult. Festschrift für Neumann. 1900.

135. Truffi. Un caso di sarcomatosi emorr. mult. prim. della cute, curato coi raggi $X$. Gazz. med. ital. 1907.

136. Wallhauser. Bicloride of mercury in the treatment of idiop. mult. haemorr. Sarcoma. Journ. amer. assoc. Nov, 1909. Ref. Derm. Zeitschrift. Bd. XVII. p. 440, 1910.

137. Weber und Da ser. Idiop. mult. pigment sarcoma of Kaposi. Brit. Journ. of Derm. Vol. XVII. p. 135. 1905.

138. Viga nò. Un caso di sarcoma idiopatico della cute. Il Morgagni. Nr. 1. 1903.

139. Wigglesworth. Archiv of Dermat. New-York. 1876. p. 97. 140. Williliams. Sarcoma cutis haemorrhagica. New-York Acad. of Med. Sect. of Derm. Ref. Journal of cut. diseases. Nr. 26. p. 40. 1908. 141. Zerbini. I fenomeni trofici del corsidetto sarcoma prim. pigment. della cute. Clin. derm. dell' Univ. d. Roma. Maggio. 1898.

142. $\mathrm{Z}$ u m b u s c h. Multiples idiopathisches Hautsarkom mit Knochenmetastasen. Archiv f. Derm. u. Syph. Bd. CVII. p. 329. 1911.

\section{Erklärung der Abbildungen auf Taf. IX-XI.}

Fig. 1. Präparat aus einem frischen, stecknadelkopfgroßen Herde des Vorderarmes (Fall III). Man sieht zwei übereinanderliegende, von der Umgebung auffallend scharf abgegrenzte Knötchen.

Fig. 2. Stelle aus dem obigen Präparat bei starker Vergrößerung. Wucherung der Endothelien und der der Gefäßwand anliegenden Zellen. Fig. 3. Präparat aus der Glans penis (Fall III). Durchwachsung der Venen durch das Geschwulstgewebe. Fortgeschrittenes Stadium.

Fig. 4. Präparat aus einem Herde der Vorhaut (Fall III). Lymphangiombildung.

Fig. 5. Präparat aus dem Sarkomherde der Leber (Fall IV).

Fig. 6. Präparat aus einem stecknadelkopfgroßen Knötchen der Lunge (Fall III). Beginnende Stadien der Geschwulstbildung.

Fig. 7. Präparat aus einem haselnufgroßen Herde der Lunge (Fall III). Geschwulstgewebe weiter entwickelt.

Die genauere Schilderung der Abbildungen ist dem Texte zu entnehmen. 


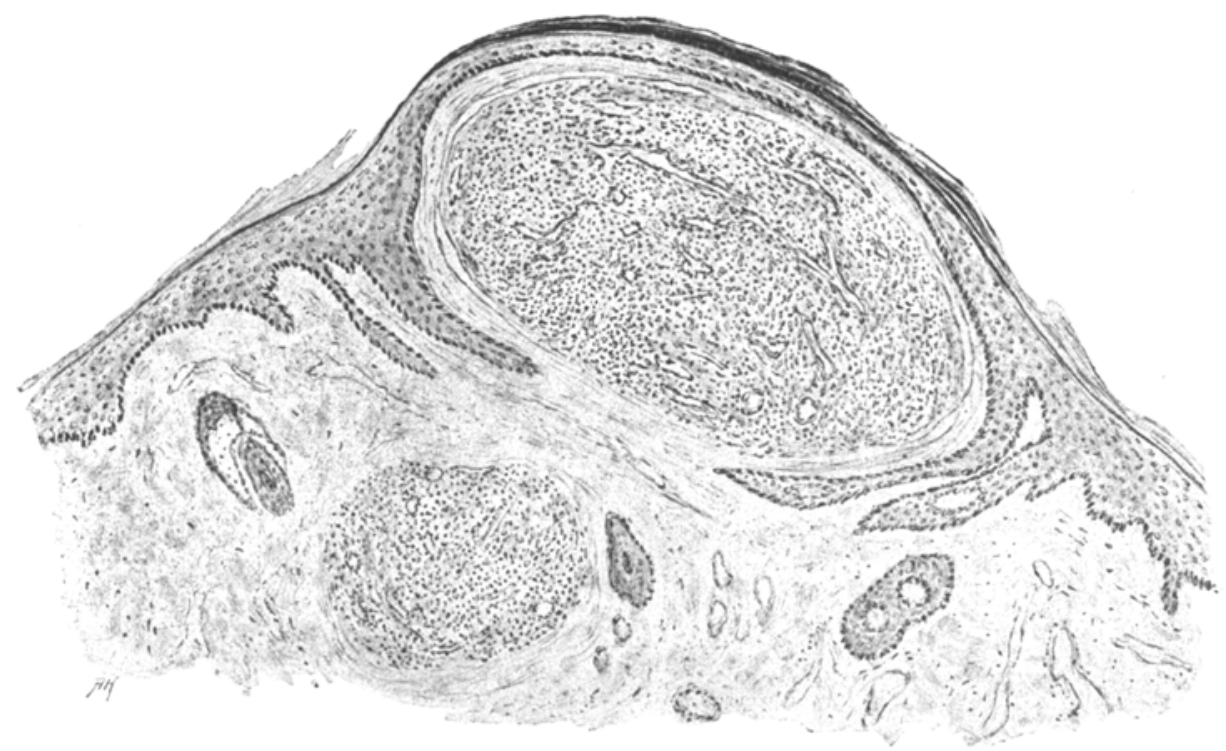

Fig. 1.

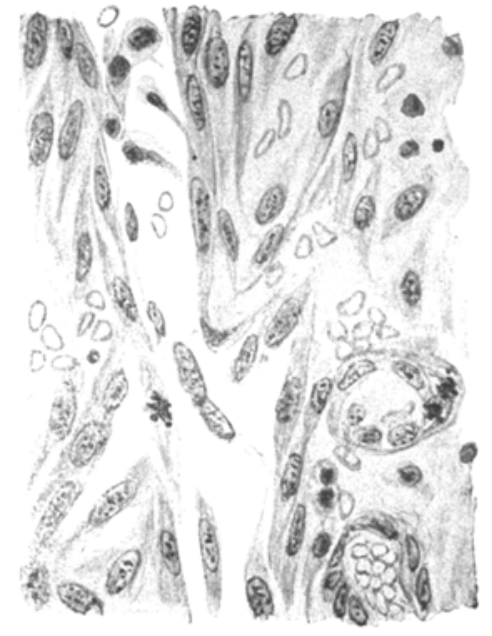

Fig. 2.

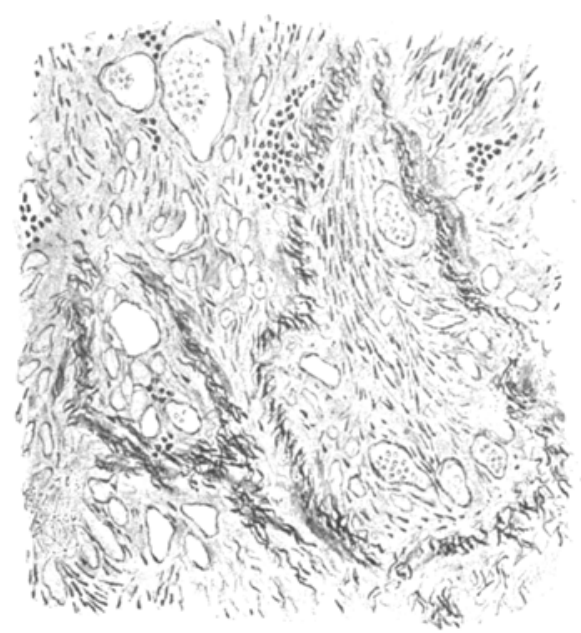

Fig. 3 .

Dalla Favera: Über das sog. Sarcoma id. mult. haem. (Kaposi). 


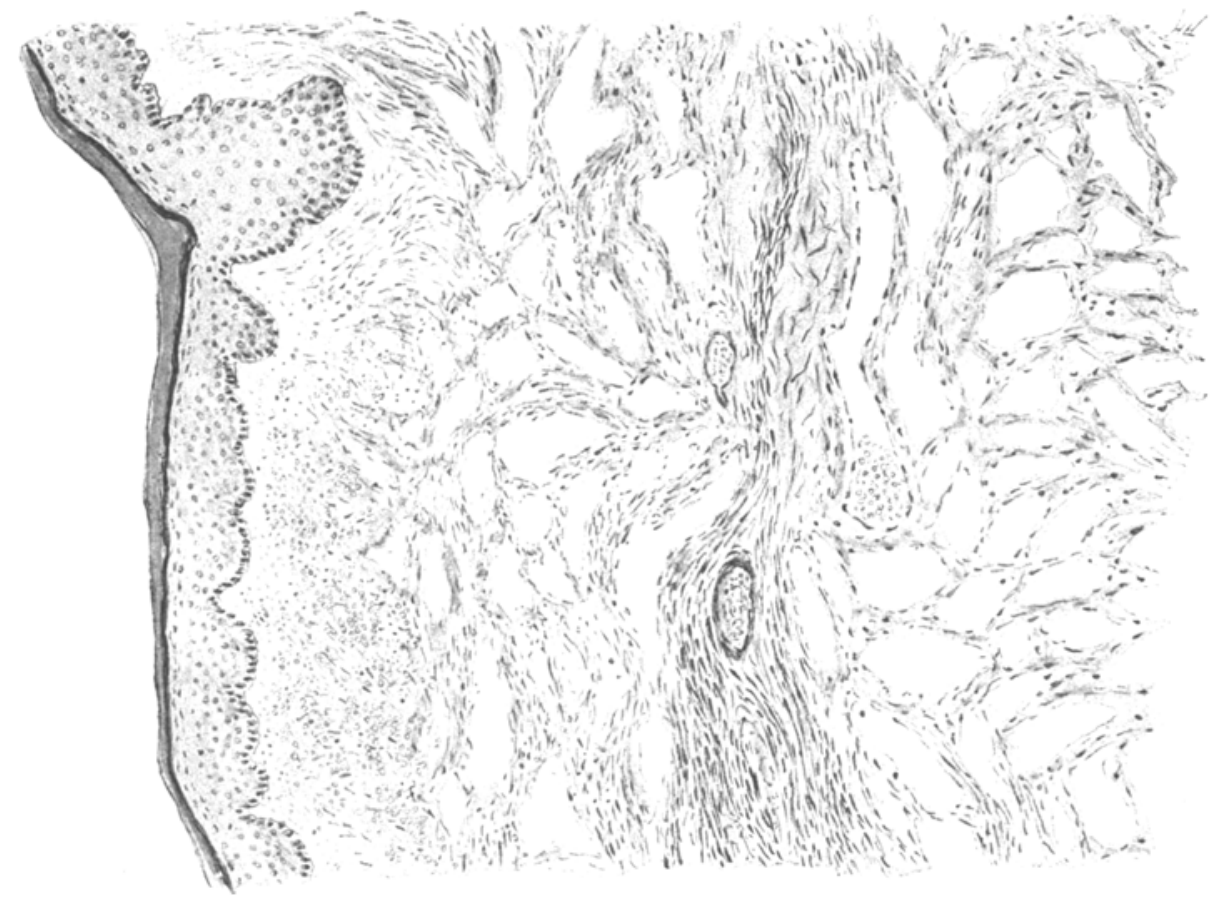

Fig. 4.

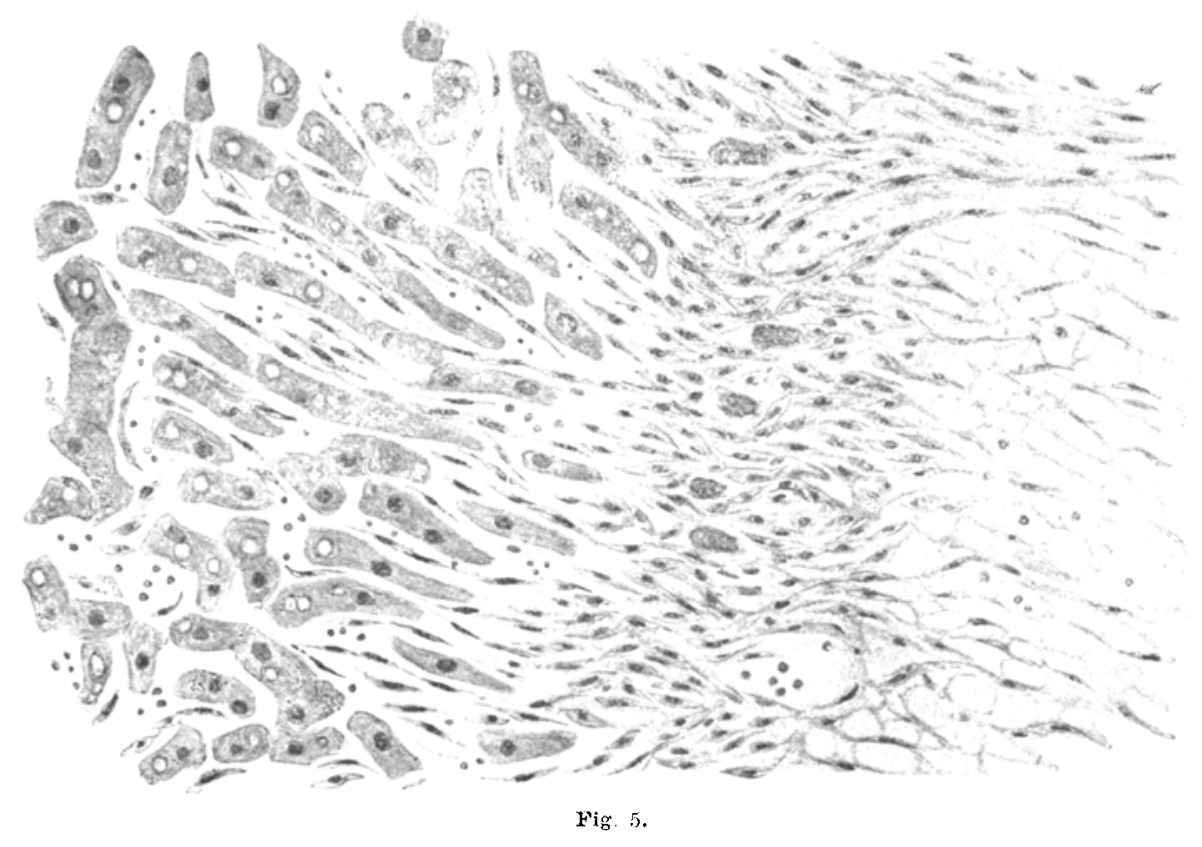

Dalla Favera: Über das sog. Sareoma id. mult. haem. (Kaposi). 


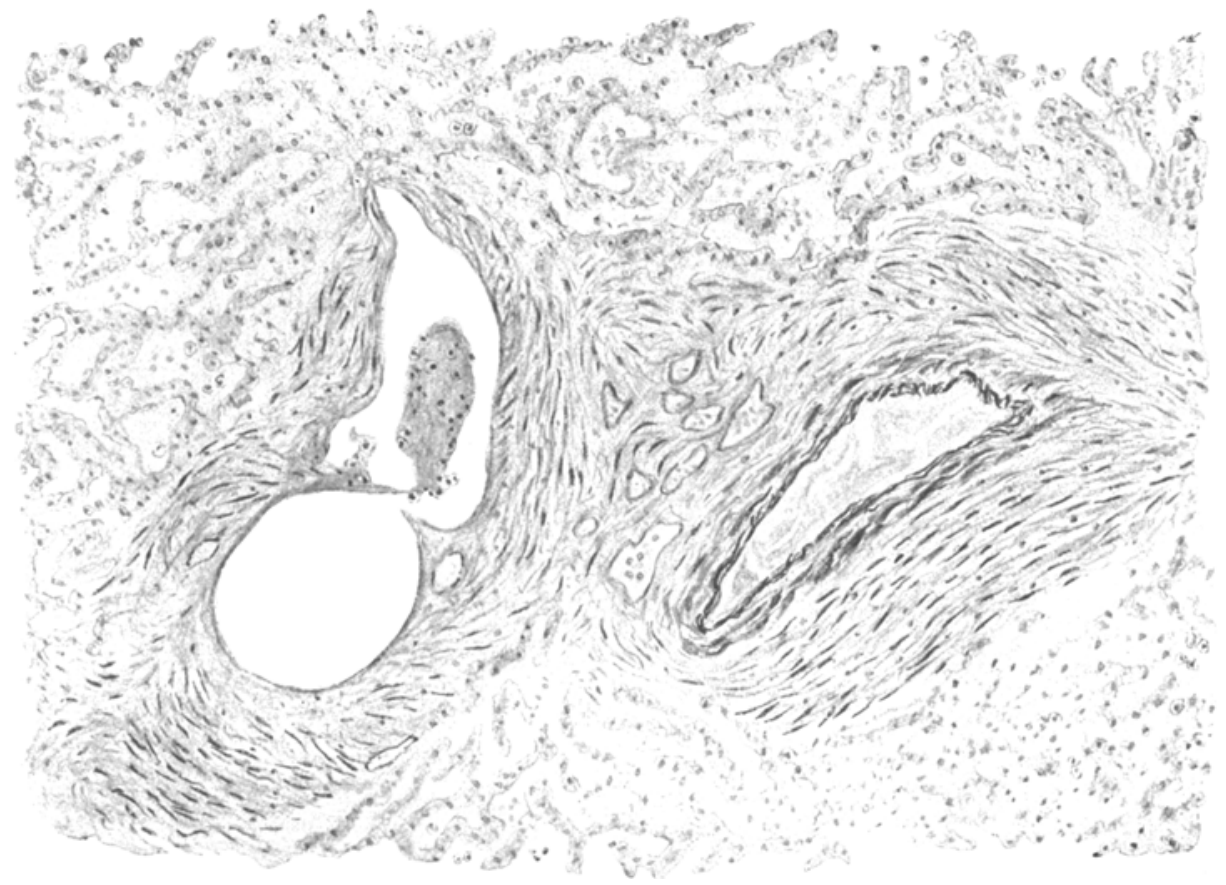

Fig. 6.

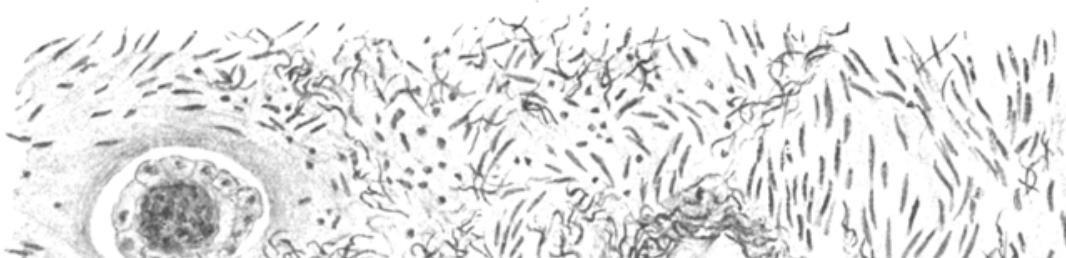

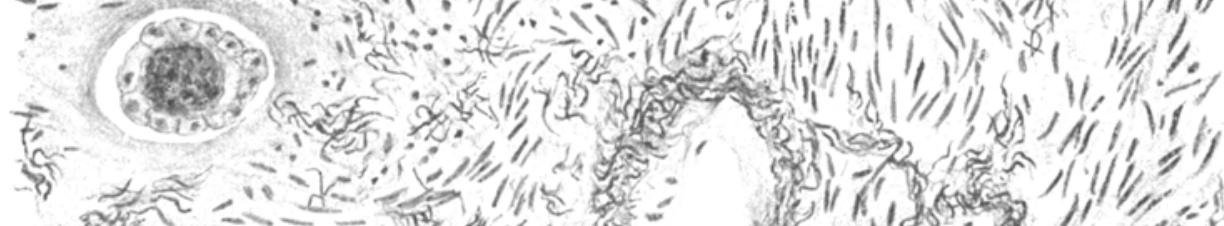

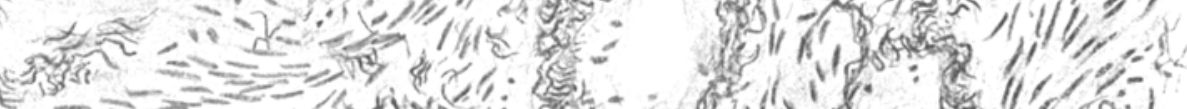

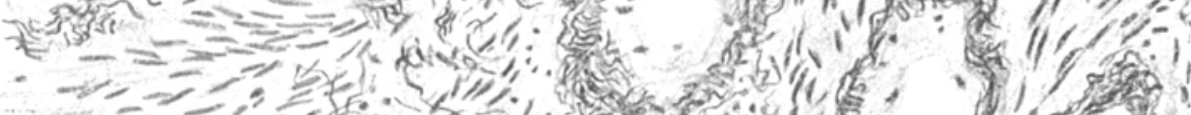

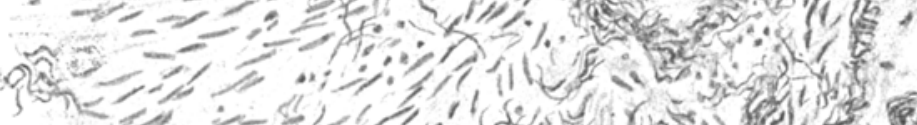
a 120

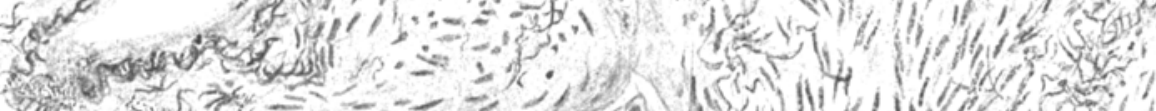

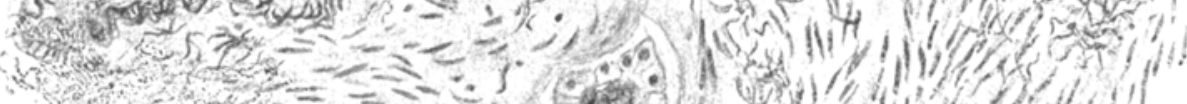

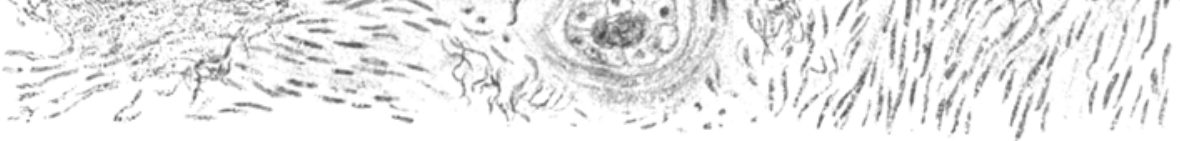

Fig. 7 .

Dalla I'avera: Über das sog. Sarcoma id. mult. haem. (Kaposi). 